\title{
CT angiography and MRI of hand vascular lesions: technical considerations and spectrum of imaging findings
}

\author{
Alain G. Blum ${ }^{1 *} \mathbb{C}$, Romain Gillet ${ }^{1}$, Lionel Athlani ${ }^{2}$, Alexandre Prestat ${ }^{1}$, Stéphane Zuily ${ }^{3}$, Denis Wahl³, \\ Gilles Dautel ${ }^{2}$ and Pedro Gondim Teixeira'
}

\begin{abstract}
Vascular lesions of the hand are common and are distinct from vascular lesions elsewhere because of the terminal vascular network in this region, the frequent hand exposure to trauma and microtrauma, and the superficial location of the lesions. Vascular lesions in the hand may be secondary to local pathology, a proximal source of emboli, or systemic diseases with vascular compromise. In most cases, ischaemic conditions are investigated with Doppler ultrasonography. However, computed tomography angiography (CTA) or dynamic contrast-enhanced magnetic resonance angiography (MRA) is often necessary for treatment planning. MR imaging is frequently performed with MRA to distinguish between vascular malformations, vascular tumours, and perivascular tumours. Some vascular tumours preferentially affect the hand, such as pyogenic granulomas or spindle cell haemangiomas associated with Maffucci syndrome. Glomus tumours are the most frequent perivascular tumours of the hand. The purpose of this article is to describe the state-of-the-art acquisition protocols and illustrate the different patterns of vascular lesions and perivascular tumours of the hand.
\end{abstract}

Keywords: Occupational disease, Thromboangiitis obliterans, Buerger's disease, Glomus tumour, Vascular tumour

\section{Key points}

- Vascular lesions of the hand are common and are distinct from vascular lesions elsewhere.

- At the level of the hamatum, the ulnar artery is located in front of the tip of the hamulus, where it is exposed to shocks on the palm of the hand.

- Computed tomography angiography of the hand is performed with two successive acquisitions after injection of iodinated contrast medium.

- An artery occlusion may be missed with magnetic resonance imaging if magnetic resonance angiography is not performed.

\footnotetext{
*Correspondence: alain.blum@gmail.com

1 Service D'imagerie Guilloz, CHRU Nancy, 54000 Nancy, France

Full list of author information is available at the end of the article
}

\section{Introduction}

Vascular lesions of the hand are common and are distinct from vascular lesions elsewhere because of the terminal vascular network in this region, the hand's frequent exposure to trauma and microtrauma, and the superficial location of the lesions. Vascular lesions in the hand may be secondary to local pathology (e.g. tumour, malformation, trauma, iatrogenic cause, or drug injection), a proximal source of emboli (e.g. dissections or aneurysms), or systemic diseases with vascular compromise (e.g. rheumatic and vaso-occlusive diseases).

Clinical history and direct observation remain the best approach for diagnosis of vascular lesions in the hand. Symptoms may suggest emboli, vessel occlusion, a vascular malformation, or a tumour. In most cases, Doppler ultrasonography (US) is the first imaging modality to be performed. Computed tomography angiography (CTA) or magnetic resonance imaging (MRI) is indicated 
to improve lesion characterisation and treatment guidance [1, 2]. MRI protocols should in most cases not only include conventional sequences but also contrastenhanced magnetic resonance angiography (MRA), which improves the evaluation of the vascular network and helps to characterise vascular malformations [3-5]. MRI is also the imaging method of choice for the evaluation of vascular tumours and the determination of their anatomic extent $[6,7]$. CTA is versatile and most often used for the evaluation of traumatic lesions and vascular occlusion $[2,8,9]$. Recently, the clinical availability of advanced CT imaging techniques, such as dynamic CTA and superhigh-resolution (SHR)-CTA, has increased. Dynamic CTA provides a functional analysis of the hand arterial network and warrants lesion evaluation at the best vascular phase $[10,11]$. SHR-CTA allows a clear visualisation of the most distal arteries.

In this article, we will review the relevant vascular anatomy, describe the state-of-the-art acquisition protocols, and illustrate the different patterns of vascular lesions of the hand in adults, while avoiding common diagnostic pitfalls.

\section{Relevant anatomy}

The vascularisation of the hand is mainly ensured by the radial and ulnar arteries (RA and UA, respectively) [12]. The UA penetrates the palm of the hand through Guyon's canal in which it travels. Guyon's canal contains the UA and its two (sometimes three) satellite veins as well as the ulnar nerve on the ulnar side. These structures are well protected from trauma at the level of the pisiform. However, at the level of the hamate, the UA is located in front of the tip of the hamulus (hook of the hamate), where it is exposed to shocks on the palm of the hand (Fig. 1; Additional file 1: Video 1) [13, 14].

The RA and the UA feed several arches that are responsible for the vascularisation of the carpus; the main ones are the superficial palmar arch (SPA) and the deep palmar arch (DPA). The SPA is mainly fed by the UA and ensures at least the vascularisation of the last three or four fingers. The SPA is covered by skin and the palmar fascia. Its most distal part projects between the proximal and distal palmar creases.

There are many anatomical variations of the SPA (Fig. 2) [12, 15]:

- The SPA may or may not vascularise the thumb.

- A persistent median artery is observed in about $10 \%$ of cases; its size is extremely variable. It may be barely perceptible or, conversely, equal to the diameter of the RA. Its origin is also variable. It is often associated with a bifid median nerve; in that case, it travels between the two nerve trunks [16].

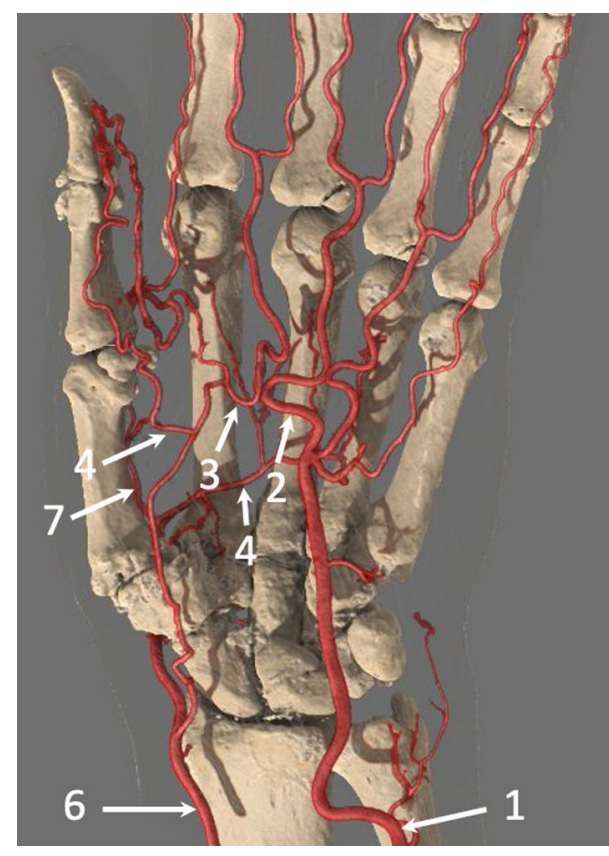

Fig. 1 SHR-CTA of the hand (with Gl) in a 69-year-old woman that shows the complex arterial network of the hand with a Type A incomplete SPA. The UA (1) feeds the ulnar side of the SPA (2), while the superficial branch of the RA feeds the radial side of the SPA (3). The SPA gives off branches into the first web space, which supply the radial side of the index finger and the thumb (4). The DPA (5) is constituted mainly from the RA (6), which forms an anastomosis with the deep branch of the UA. It generates the FPMA (7). Note the close relationship between the UA and the hamulus. Note also carpal degenerative changes and joint calcifications due to calcium pyrophosphate deposition disease

- The SPA can be supplied by the RA and/or the persistent median artery.

The DPA is mainly supplied by the RA and ensures vascularisation of the first two fingers. The DPA travels to the palmar surface of the bases of the metacarpal bones deep to the deep flexor tendons. It gives rise to four palmar metacarpal branches. The first palmar metacarpal artery (FPMA) ensures vascularisation of the thumb and feeds the palmoradial digital artery of the index finger. The palmar metacarpal arteries of the second, third, and fourth spaces each receive a perforating branch originating from the corresponding dorsal interosseous artery before anastomosing with the corresponding common digital artery originating from the SPA. These arteries are then divided into palmar collateral arteries.

The thumb arterial system may be supplied by the DPA, the SPA, and the dorsal system (Fig. 1). The FPMA and the first dorsal metacarpal artery are the main branches that provide the thumb vasculature. The FPMA is dominant in $65 \%$ of cases. The palmar arteries of the thumb are 


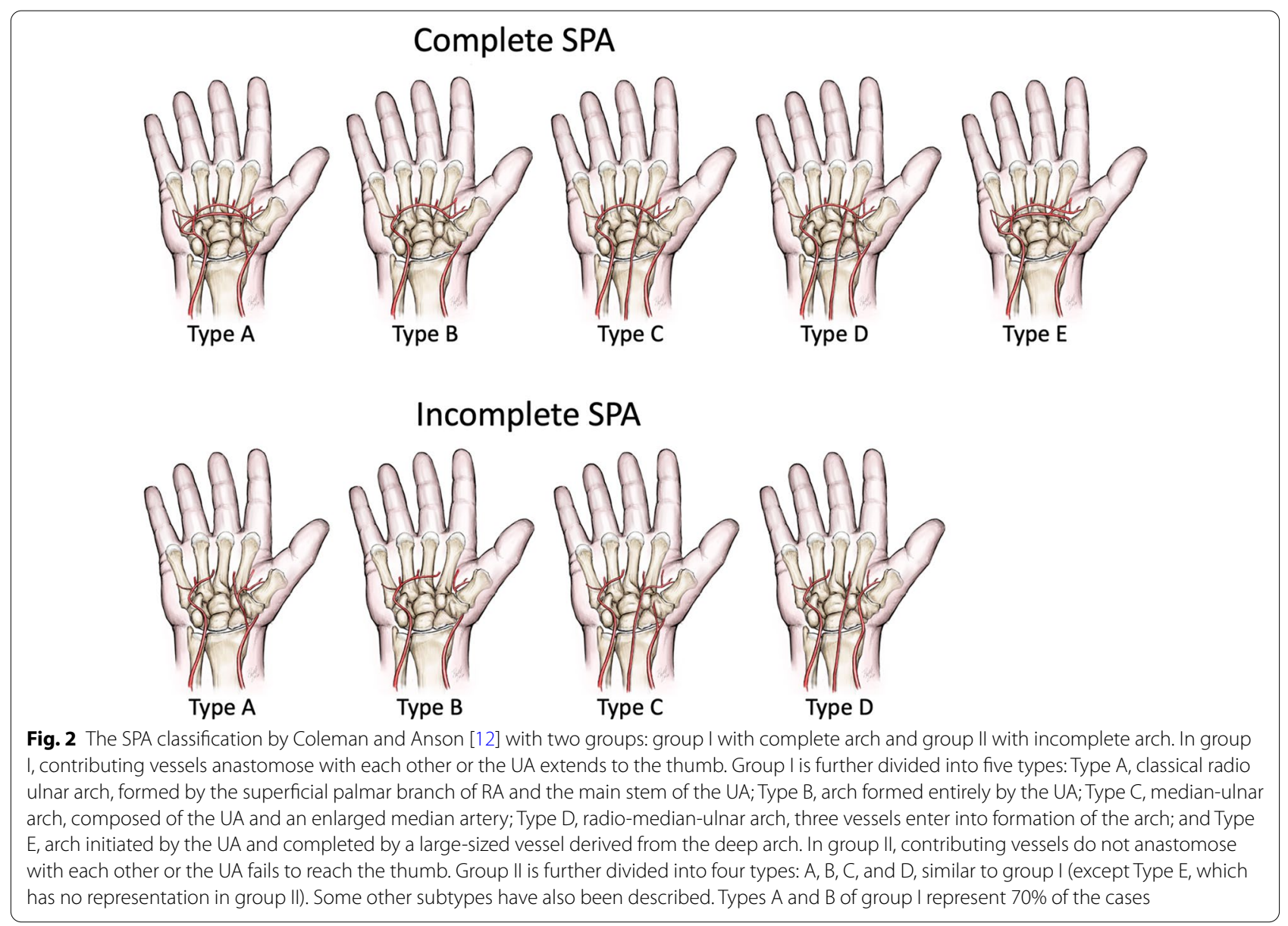

almost always present and large, unlike the inconsistent dorsal arteries that have a small diameter. In most cases, the widest artery is the ulnopalmar digital artery [17]. The fingers are vascularised by two palmar and two dorsal arteries. The palmar arteries are more important. The dorsal arteries of the long fingers only vascularise the dorsal aspect of the first phalanx.

\section{Imaging protocols}

CTA and MRI are both efficient methods to evaluate hand vessels and lesions with a vascular origin. However, advanced CT techniques, such as dynamic CTA and SHR-CTA, have increased the frequency with which CTA is performed (Table 1). In any case, to guarantee a high-quality examination, hand imaging should be carried out independently and not as part of a complete upper limb imaging protocol. For both CTA and MRA of the hand, it is important to avoid patients with cold

Table 1 Comparison of different imaging methods (except ultrasonography) to evaluate hand vessels

\begin{tabular}{llllll}
\hline $\begin{array}{l}\text { Imaging methods for hand vessel } \\
\text { analysis }\end{array}$ & Angiography & Classic CTA & Dynamic CTA & SHR-CTA & MRA \\
\hline Injection site & Intra-arterial & Intravenous & Intravenous & Intravenous & Intravenous \\
Spatial resolution & +++ & ++ & ++ & ++ & + \\
Temporal resolution & +++ & + & +++ & ++ & ++ \\
3D analysis & +++ & +++ & +++ & ++ & ++ \\
Bone and soft tissue evaluation & + & ++ & +++ & ++ \\
\hline
\end{tabular}


hands and those who smoked tobacco or cannabis prior to the examination because these conditions can generate vasoconstriction, which is detrimental to the exploration of the digital arteries. Hand warming or $1 \mathrm{~min}$ of squeezing exercises results in physiologic vasodilation, which is useful to improve visualisation of small vessels $[8,18]$.

\section{(A) $\quad$ CTA}

Single scan upper limb CTA can be performed with sufficient quality up to the distal portion of the RA and UA but no further. This is because it is difficult to estimate the ideal timing to achieve satisfactory enhancement of both the proximal and distal arteries and digital artery evaluation requires optimised spatial resolution, which is not achievable with an upper limb run-off (Fig. 3).

CTA of the hand if possible is performed in prone position with flat hand on the table with fingers extended (superman position) in order to place the hand as much as possible in the centre of the scanner to increase spatial resolution (Figs. 1 and 3). A bilateral exploration can occasionally be performed with the patient kneeling on the table, elbows slightly flexed, forearms resting on table, and hands together in the prayer's position (Fig. 4; Table 2).
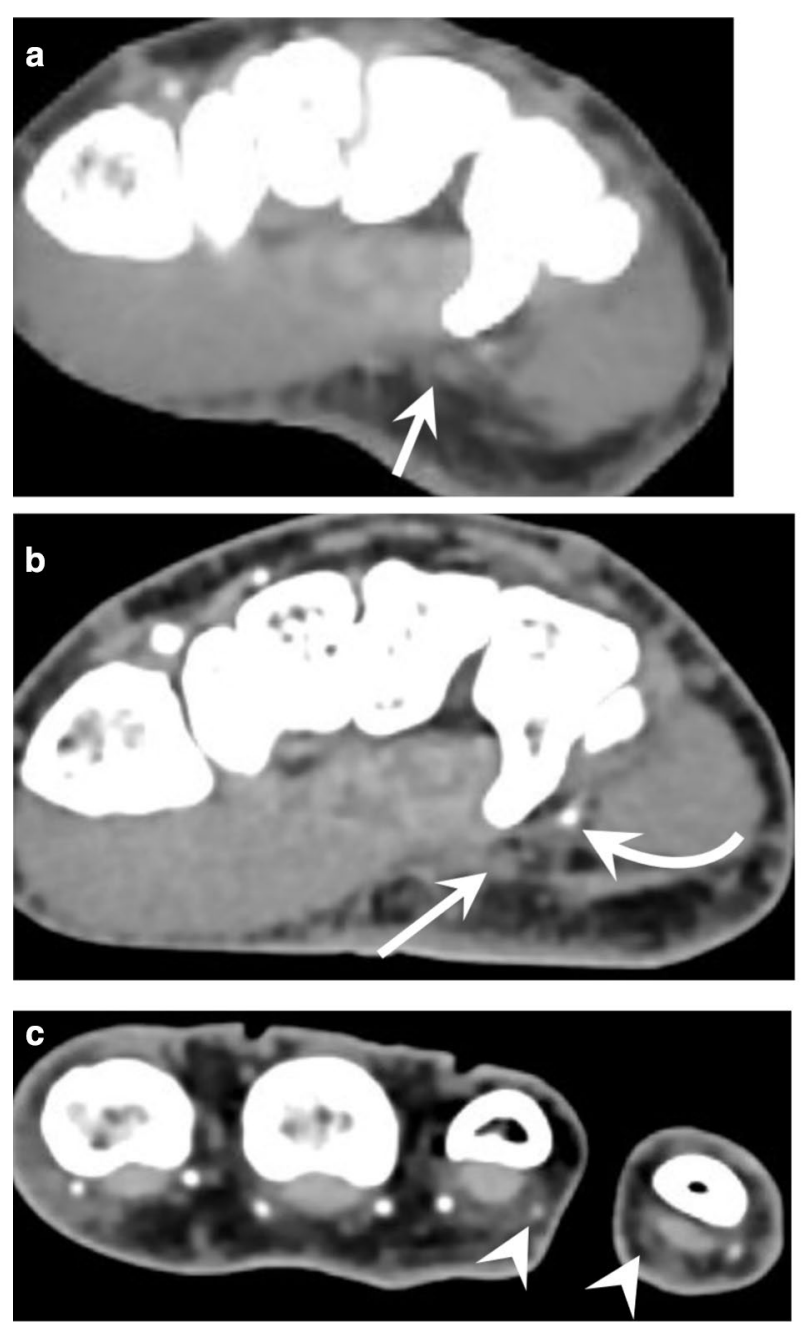

Fig. 3 Comparison of the image quality between a complete upper extremity run-off and a CTA of the hand in a 52-year-old patient with HHS, presenting with ischaemia of the fourth and fifth fingers. a A complete upper extremity run-off was first obtained showing a probable occlusion of the UA. b, c CTA of the hand showed a 6-cm-long occlusion of the UA, the patency of the deep branch of the UA (curved arrow), which is fed by the DPA, the occlusion of the ulnopalmar artery of the fifth finger and the distal occlusion of the radiopalmar artery of the fourth finger (arrowheads). d GI providing an overview of the lesions and of the arterial configuration of the hand showing the deep branch of the UA (curved arrow) and the occlusion of the ulnopalmar artery of the fifth finger (arrowhead)

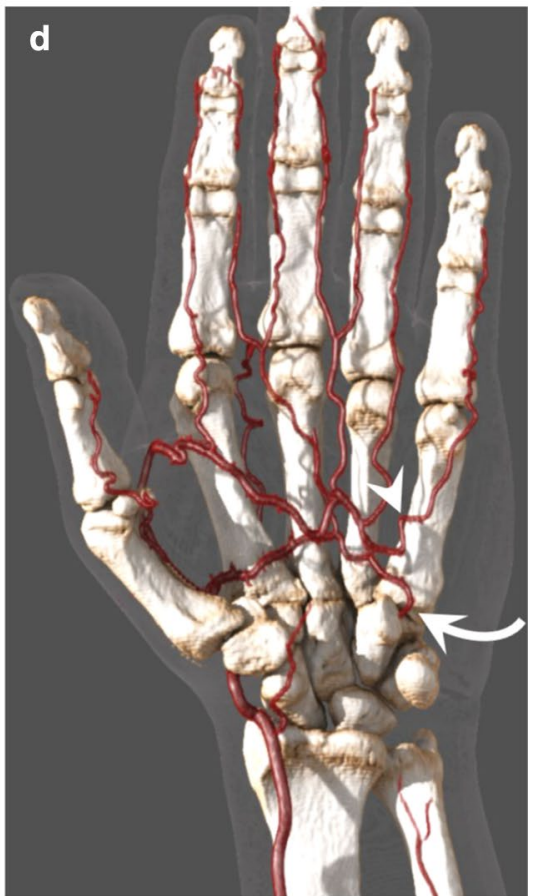




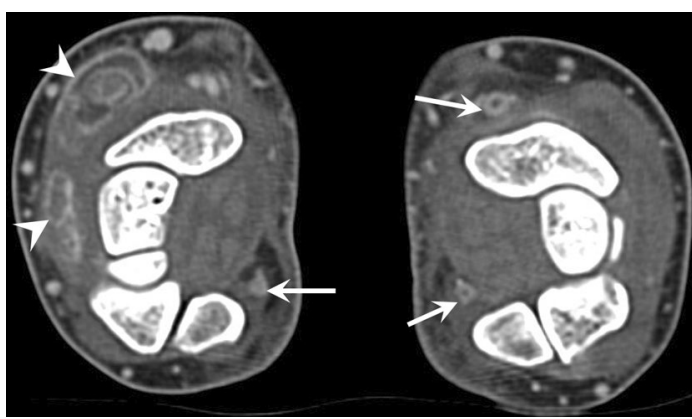

Fig. 4 Buerger's disease in a heavy smoker 41-year-old woman presenting with ischaemic ulcers of the fingers and arthralgia. Bilateral CTA shows occlusion and wall thickening of the right RA and of both UA (straight arrows). Note also a tenosynovitis of the extensor carpi radialis and of the extensor digitorum of the right wrist (arrowheads)

Optimal injection and acquisition parameters are critical when imaging the hand [19]. Iodinated contrast medium (ICM) should be injected into a contralateral peripheral vein. Alternatively, injection can also be performed in an ipsilateral antecubital vein, more proximal relative to the study area. Around $1.2-1.3 \mathrm{ml} / \mathrm{kg}$ body weight of ICM, with a concentration of at least $350 \mathrm{mg}$
$\mathrm{I} / \mathrm{ml}$, is injected with a flow rate of $4-5 \mathrm{ml} / \mathrm{s}$ followed by a 30-ml saline flush. A test-bolus or bolus-tracking technique is mandatory. For helical CTA, a simple and efficient approach is to use bolus tracking with UA and RA visual monitoring and manual triggering.

In helical mode, two successive acquisitions are carried out after ICM injection, in the same direction from the proximal to distal location. Even with a delay after contrast injection over $10 \mathrm{~s}$, the contrast bolus can be outrun during the first acquisition. A double acquisition allows a better distinction between arteries and veins, as well as between delayed opacification and occlusion of the digital arteries. A late acquisition may also be useful for detecting arterial wall thickening and enhancement in cases of occlusion or an inflammatory arterial wall disease. A low-dose technique with 80 or $100 \mathrm{kVp}$ increases the contrast at the enhanced vessels and reduces patient exposure [18].

SHR-CTs are novel commercial systems with $0.25-\mathrm{mm}$ detector elements in the in-plane and longitudinal directions. Images can be reconstructed with high matrix sizes (up to $2048 \times 2048$ ) using deep-learning reconstruction algorithms. SHR improves the quality of both native images and multiplane reformats, especially the

Table 2 Protocols for CTA of the hand

\begin{tabular}{|c|c|c|c|}
\hline Scan protocols & Classic helical CTA & Dynamic CTA & Helical CTA with SHR \\
\hline Precautions before scanning & \multicolumn{3}{|c|}{ Avoid cold and smoking; warm the hand; exercise by squeezing a ball } \\
\hline Hand position & \multicolumn{3}{|c|}{ Prone position, hand as close as possible to the centre of the gantry } \\
\hline Acquisition direction & Cranial-caudal & Not applicable & Cranial-caudal \\
\hline Number of acquisitions after ICM injection & 2 & $8-12$ & 2 \\
\hline Delay between each acquisition & $12 \mathrm{~s}$ & $5 \mathrm{~s}$ & $15 \mathrm{~s}$ \\
\hline Scanning range & $20-25 \mathrm{~cm}$ & $4-16 \mathrm{~cm}$ & $20-25 \mathrm{~cm}$ \\
\hline Detector coverage and slice thickness & $80 \times 0.5 \mathrm{~mm}$ & $80-320 \times 0.5 \mathrm{~mm}$ & $160 \times 0.25 \mathrm{~mm}$ \\
\hline Pitch & Detail (0.637) & 0 & Detail (0.569) \\
\hline Scanning time for each acquisition & $10 \mathrm{~s}$ & $0.5 \mathrm{~s}$ & $13.5 \mathrm{~s}$ \\
\hline Scanning FOV & Ideally < $12 \mathrm{~cm}$ & Ideally $<12 \mathrm{~cm}$ & Ideally $<12 \mathrm{~cm}$ \\
\hline Focal spot & Small & Small & Ultra-small \\
\hline Matrix size & $512 \times 512$ & $512 \times 512$ & $1024 \times 1024$ \\
\hline$k \vee p$ & 100 & 80 & 100 \\
\hline $\mathrm{mAs}$ & $70-130$ & 75 & $100-200$ \\
\hline Rotation time & $0.5 \mathrm{~s}$ & $0.5 \mathrm{~s}$ & $1 \mathrm{~s}$ \\
\hline CM amount & \multicolumn{3}{|l|}{$1.2-1.3 \mathrm{ml} / \mathrm{kg}$ body weight } \\
\hline Saline flush & \multicolumn{3}{|l|}{$30 \mathrm{ml}$} \\
\hline Flow rate & \multicolumn{3}{|l|}{$4-5 \mathrm{ml} / \mathrm{sec}$} \\
\hline Arterial scanning delay & Manual bolus tracking & $\begin{array}{l}\text { Test bolus or } \\
\text { manual bolus } \\
\text { tracking }\end{array}$ & Manual bolus tracking \\
\hline Reconstruction algorithms & \multicolumn{3}{|c|}{ Iterative or DLR reconstruction with standard and high-resolution kernels } \\
\hline Post-processing & \multicolumn{3}{|l|}{ MPR, MIP, GI, bone subtraction } \\
\hline
\end{tabular}


depiction of small vessels, particularly the distal portion of the digital arteries (Fig. 5; Additional file 1: Video 1) [20].

Dynamic CTA simultaneously yields an anatomic and a functional vascular evaluation $[10,11,18]$. Large detector CT scanners (e.g. CT perfusion) allow multiphasic arterial exploration with up to $16 \mathrm{~cm}$ of Z-axis coverage without compromising spatial or temporal resolution. Indeed, dynamic CTA warrants a short volume acquisition time (0.27-1 s) with temporal uniformity (e.g. all voxels of a given volume are acquired almost at the same time), and a free choice of inter-volume delay. A 5-s
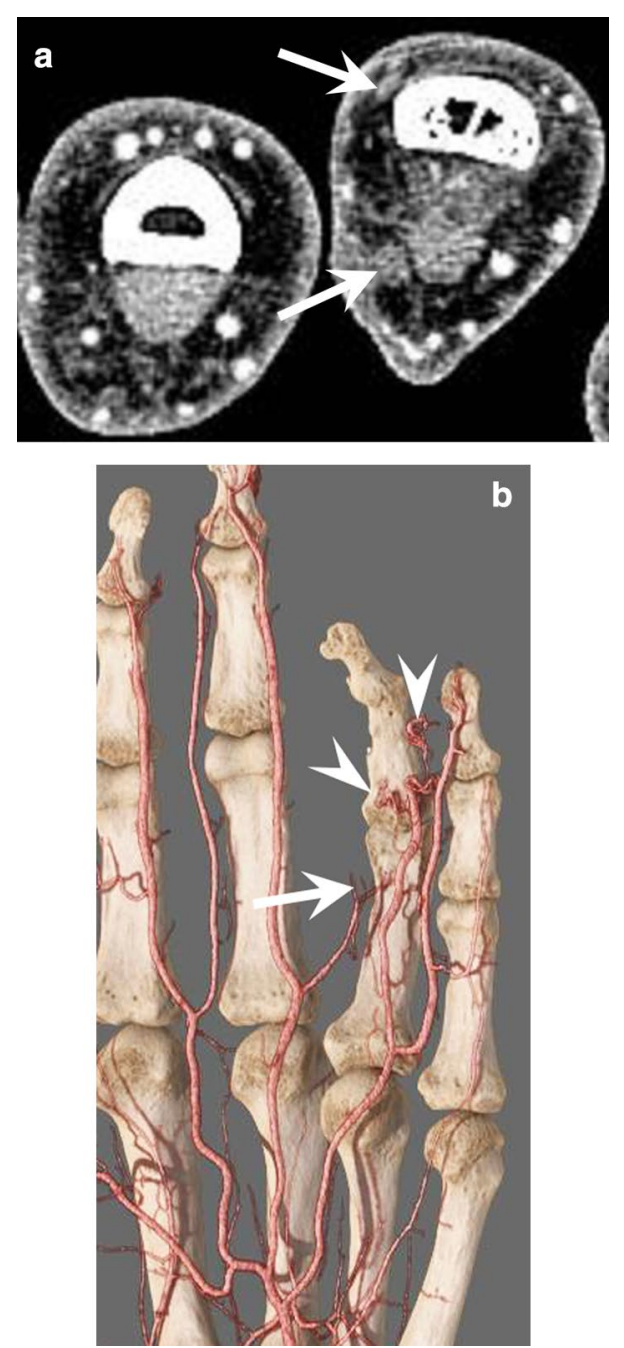

Fig. 5 Traumatic occlusion of the radial digital arteries of the fourth finger in a 29-year-old man. a SHR-CTA at the level of the first phalanx showing the occlusion of the radiopalmar and radiodorsal digital arteries of the fourth finger (arrows) as well as a reduction of the venous flow. $\mathbf{b}$ Gl showing the occlusion of the radiopalmar artery at the level of the first phalanx and of the ulnopalmar artery associated with corkscrew collaterals (arrowheads) inter-volume delay is a good trade-off between temporal resolution and radiation dose. If bone subtraction techniques are applied, images with a pseudo-angiographic effect can be generated (Fig. 6). Dynamic CTA of the hand can be useful to evaluate vascular malformations because it allows visualisation of the lesion at the best vascular phase (Fig. 6; Additional file 2: Video 2). It also provides a functional evaluation of the arterial network of the hand in the preoperative evaluation of hypothenar hammer syndrome (HHS). The same technique applied at the shoulder girdle has also been shown to be effective in diagnosing thoracic outlet syndrome [21].

Post-processing is required to visualise and interpret SHR-CTA datasets and to communicate findings to referring physicians $[8,9,22,23]$. Post-processing includes multiplanar reconstruction (MPR), maximum
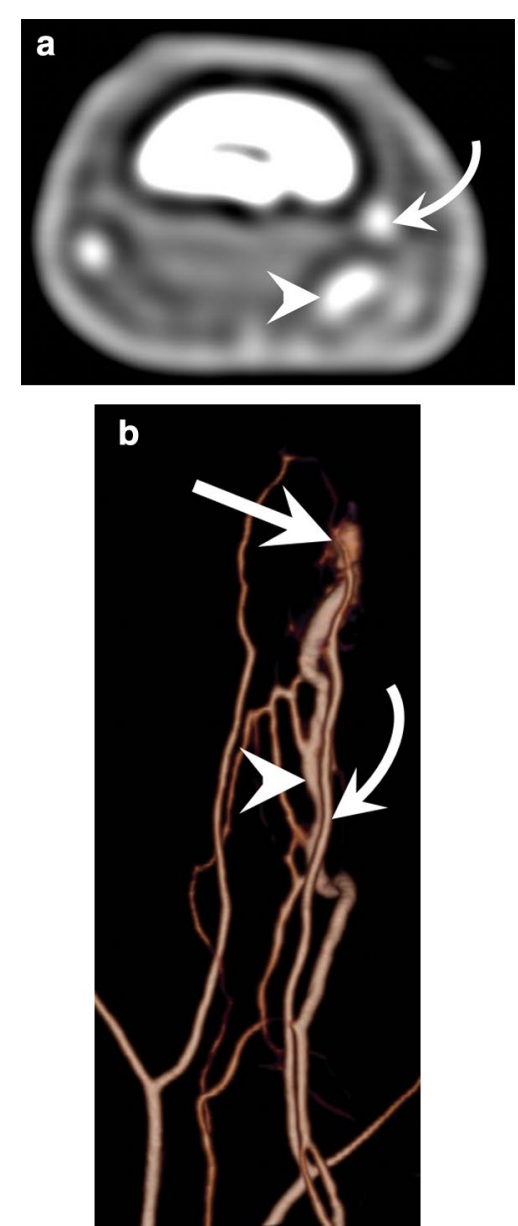

Fig. 6 Dynamic CTA of an arteriovenous fistula (straight arrow) fed by the ulnopalmar digital artery (curved arrow) of the fourth finger in a 32-year-old patient. $\mathbf{a}, \mathbf{b}$ Native slice and VRT image with bone subtraction at the early arterial phase showing the fistula and the early enhancement of an ulnopalmar vein (arrowhead). Dynamic CTA allows capturing the lesion at the best vascular phase 
intensity projection (MIP) images, and volume rendering technique (VRT), which has been replaced by global illumination rendering (GI) $[24,25]$. In all cases, threedimensional (3D) images must be analysed in comparison with native slices due to possible artefacts in small vessel segmentation. This endeavour requires high spatial resolution, good vascular enhancement, and satisfactory signal-to-noise ratio to be effective.

Finally, the radiation dose to the patient remains low, ranging from 0.05 to $0.3 \mathrm{mSv}$, due to low-dose techniques and a low hand radiosensitivity at the level of the hand [11].

\section{(B) MRI}

The patient should be scanned in a comfortable position to avoid motion artefacts. A dedicated coil is essential to obtain high-quality images regardless of the field strength of the MRI system (Fig. 7). A flexible coil is used for the hand, and a wrist coil is used for the wrist or the thumb.

In most cases, MRA is not the only acquisition to be performed and the protocol also comprises conventional sequences with T1-weighted, fluid-sensitive sequences such as fat-suppressed T2-weighted MRI scans, and contrast-enhanced T1-weighted fat-suppressed sequences (Table 3). These morphologic sequences allow the characterisation of soft tissue masses and also the evaluation of the para-arterial environment (e.g. extrinsic compression, inflammatory changes). In addition, contrastenhanced T1-weighted fat-suppressed sequences provide a means to evaluate thickening and enhancement on the arterial wall.

The technical aspects and specific protocols for MRA have been well described in the literature $[3,4,26,27]$. MRA is usually based on the administration of a gadolinium-based contrast agent and time-resolved approaches. Time-resolved sequences use various patterns of partial $\mathrm{K}$-space filling with an oversampling of the K-space centre; the approach generates images with good temporal and spatial resolution compromise. Images can be analysed with subtraction technique, which improves contrast resolution, or without subtraction technique, thus allowing visualisation of the background. Although not recommended for quantitative perfusion analysis, timeresolved sequences are ideal for visual analysis of the hand vasculature and provide a vascular map and haemodynamic information, including inflow in the vessels or arrival times to the tissue $[1,3,18]$. For the evaluation of the hand, we use a time-resolved 3D sequence with a repetition time (TR) of 4.4-7.9 $\mathrm{ms}$ and a minimal echo time (TE min), 20-30 flip angle, a field of view (FOV) of approximately $15 \mathrm{~cm}$, an approximately $224 \times 256$
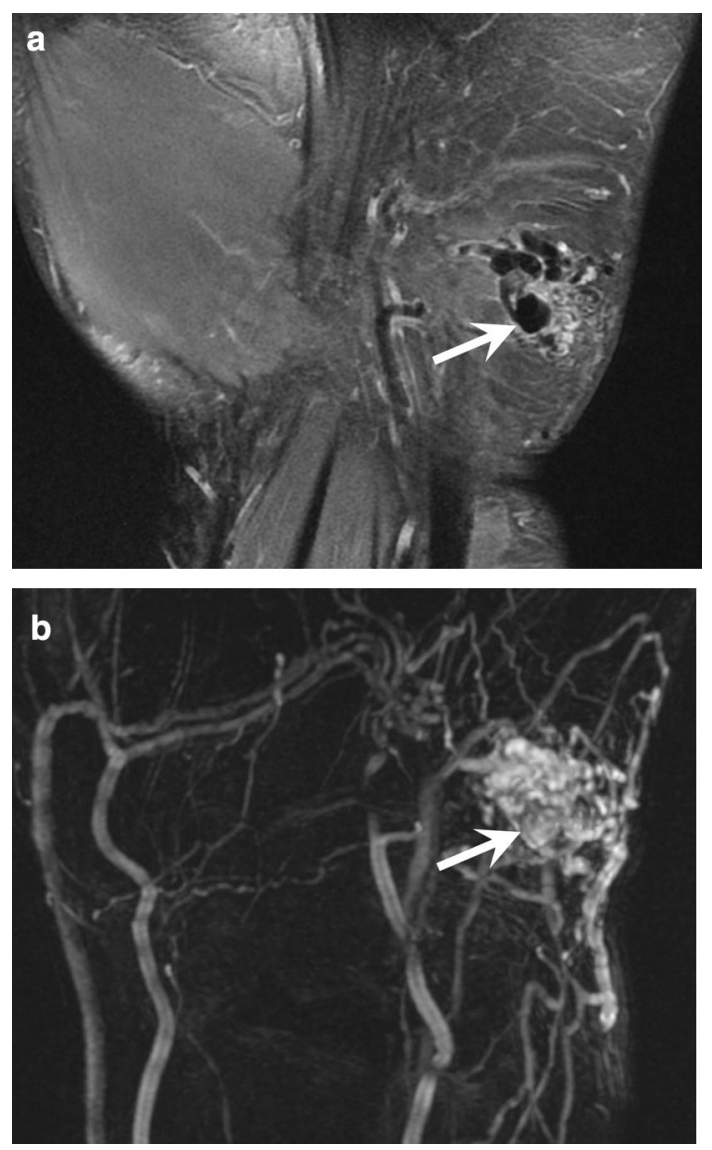

Fig. 7 AVM of the hypothenar eminence in a 37 year-old-woman. a Coronal T2-weighted MR image showing the nidus with multiple enlarged vessels with flow void (arrow) indicating a high-flow malformation. $\mathbf{b}$ MRA demonstrating the high flow of the malformation with a rapid vascular enhancement of the nidus (arrow), multiple feeding arteries, and early venous drainage through dilated veins

matrix, and a 1.8-2.0-mm slice thickness. In general, an injection of $0.1 \mathrm{mmol} / \mathrm{kg}$ of contrast agent at a rate of $1.5-2 \mathrm{ml} /$ second provides arterial imaging with high vessel to background contrast. The use of an injection pump is necessary, and the delay between acquisition start and contrast injection is dependent on the length of the mask acquisition, which usually lasts around $40 \mathrm{~s}$ (variations depending on coverage and slice thickness). For optimal evaluation of the hand, contrast injection starts $30 \mathrm{~s}$ after the beginning of the mask sequence.

\section{Different disease entities}

The diagnosis of vascular lesions of the hand is often based on clinical history and clinical examination. Most of the pathologies require US examination which in many cases is sufficient to reach the diagnosis. However, CTA and MRA which provide distinct advantages over 
Table 3 Suggested MR imaging protocol for wrist imaging at $3 \mathrm{~T}$

\begin{tabular}{|c|c|c|c|c|c|c|}
\hline Planning & Type of sequence & FOV $(\mathrm{cm})$ & TR (ms) & $\mathrm{TE}(\mathrm{ms})$ & $\begin{array}{l}\text { Slice thickness } \\
(\mathrm{mm})\end{array}$ & Matrix \\
\hline $\mathrm{AxT1}$ & SE or FSE & $10-15$ & 600 & 15 & $2.5-3$ & $384 \times 192$ \\
\hline $\mathrm{AxT} 2 \mathrm{FS}$ & FSE & $10-15$ & 6000 & 70 & $2.5-3$ & $384 \times 224$ \\
\hline CorT2 FS & FSE & $10-15$ & 6000 & 70 & $2.5-3$ & $384 \times 224$ \\
\hline Cor MRA & $\begin{array}{l}\text { time-resolved 3D sequence } \\
\text { (TRICKS) }\end{array}$ & 15 & $4.4-7.9$ & minimal & $1.8-2$ & $256 \times 224$ \\
\hline$A x T 1 C+F S$ & SE or FSE & $10-15$ & 600 & 15 & $2.5-3$ & $384 \times 224$ \\
\hline
\end{tabular}

Ax axial, Cor coronal, FOV field of view, SE spin-echo, FSE fast spin echo, TR repetition time, TE echo time, T1 C + FS contrast-enhanced T1-weighted fat-suppressed sequence

ultrasound may be indicated, and we will focus on their findings in the different entities. It should also be noted that incidental discovery of a vascular lesion on MRI is not uncommon and radiologists must be aware of this situation.

This chapter is divided into two parts. The first part covers vessel injuries and ischaemia causing lesions. The second one describes the vascular malformations and the vascular and perivascular tumours affecting the hand.

\section{(A) Ischaemic phenomena}

The causes of hand ischaemia are varied (Table 4). The three main causes of digital ischaemia, which alone represent almost two-thirds of patients with hand ischaemia, are autoimmune disorders (foremost among which is systemic sclerosis [SSc]), occupational causes, and Buerger's disease. It is likely that traumatic or microtraumatic arterial injury in the hand is widely underdiagnosed because: (1) the causative trauma is often unrecognised; (2) symptoms may be delayed, minor, or non-specific; (3) the clinical presentation may mimic other causes of digital ischaemia; and (4) imaging findings may be subtle or confusing.

\section{Peripheral embolism}

Peripheral emboli affect the upper extremities in up to $20 \%$ of cases, $70 \%$ of which are cardioembolic while $30 \%$ are caused by vascular lesions (proximal aneurysm, traumatic lesion, etc.) [28]. Therefore, imaging of the arteries of the entire upper limb is necessary in the event of suspected embolism due to lesions of the large vessels.

Table 4 Causes of hand ischaemia and indication for CTA or MRA

\begin{tabular}{|c|c|c|}
\hline Causes of hand ischaemia & Underlying aetiology & CTA or MRA \\
\hline Peripheral emboli & $\begin{array}{l}\text { Cardiac disease } \\
\text { Thoracic outlet syndrome } \\
\text { Atherosclerosis } \\
\text { Aneurysm and pseudoaneurysm of proximal arteries of } \\
\text { the upper limb }\end{array}$ & $\begin{array}{l}\text { NI } \\
\text { Dynamic CTA of the thoracic outlet } \\
\text { CTA of the entire upper limb } \\
\text { CTA of the entire upper limb }\end{array}$ \\
\hline latrogenic & $\begin{array}{l}\text { Radial access for monitoring or catheter-based proce- } \\
\text { dures }\end{array}$ & CTA may be indicated in cases of pseudoaneurysm \\
\hline Acute and subacute trauma & Lacerations, fracture, crush injury, etc & CTA \\
\hline Occupational & $\begin{array}{l}\text { HHS } \\
\text { HAVS }\end{array}$ & $\begin{array}{l}\text { CTA or MRA of the hand } \\
\text { CTA or MRA of the hand }\end{array}$ \\
\hline Intra-arterial injections of drugs & $\begin{array}{l}\text { Voluntary or accidental intra-arterial injection of drugs } \\
\text { into an artery in the hand or upper limb }\end{array}$ & CTA may be indicated in cases of pseudoaneurysm \\
\hline Thromboangiitis obliterans & Occlusion of small- and medium-sized arteries & CTA or MRA of the entire upper limb and of the hand \\
\hline Autoimmune and rheumatic diseases & $\begin{array}{l}\text { Systemic sclerosis } \\
\text { Systemic lupus erythematosus } \\
\text { Vasculitis (PAN), Sjogren's syndrome }\end{array}$ & $\begin{array}{l}\text { Usually NI but CTA or MRA may be performed to rule } \\
\text { out vasculitis mimics }\end{array}$ \\
\hline Drug/chemical-related & $\begin{array}{l}\text { Amphetamines, beta-blockers, bleomycin, cisplatin, } \\
\text { cyclosporine, interferon, methysergide, polyvinyl } \\
\text { chloride }\end{array}$ & $\mathrm{NI}$ \\
\hline Vaso-occlusive disease & $\begin{array}{l}\text { Cold agglutinin disease, cryofibrinogenemia, malig- } \\
\text { nancy (including paraneoplastic phenomenon), etc. }\end{array}$ & $\mathrm{NI}$ \\
\hline Other causes & Frostbite & $\mathrm{NI}$ \\
\hline
\end{tabular}

$N /$ not indicated 
Radiologists should specifically search for aneurysms of the axillary artery or posterior circumflex artery in sports with overhead arm motion such as volleyball and tennis (Fig. 8) [29].

\section{latrogenic causes}

Radial and ulnar arterial access is frequently used for catheterisation, and transradial access is increasingly used for coronary angiography and percutaneous coronary intervention [30]. Iatrogenic conditions are mainly represented by occlusion of the RA. This phenomenon occurs in $6 \%-8 \%$ of cases after radial catheterisation [31, 32]. It must be prevented by appropriate anticoagulation and should be detected by US before the patient is discharged. It is generally silent, but it affects the vascular reserve of patients who may have to undergo further vascular exploration [31, 32]. Post-catheterisation aneurysm is exceptional and generally occurs in an infectious context. Iatrogenic vascular-surgery-related hand complications also include RA harvest for coronary artery bypass,
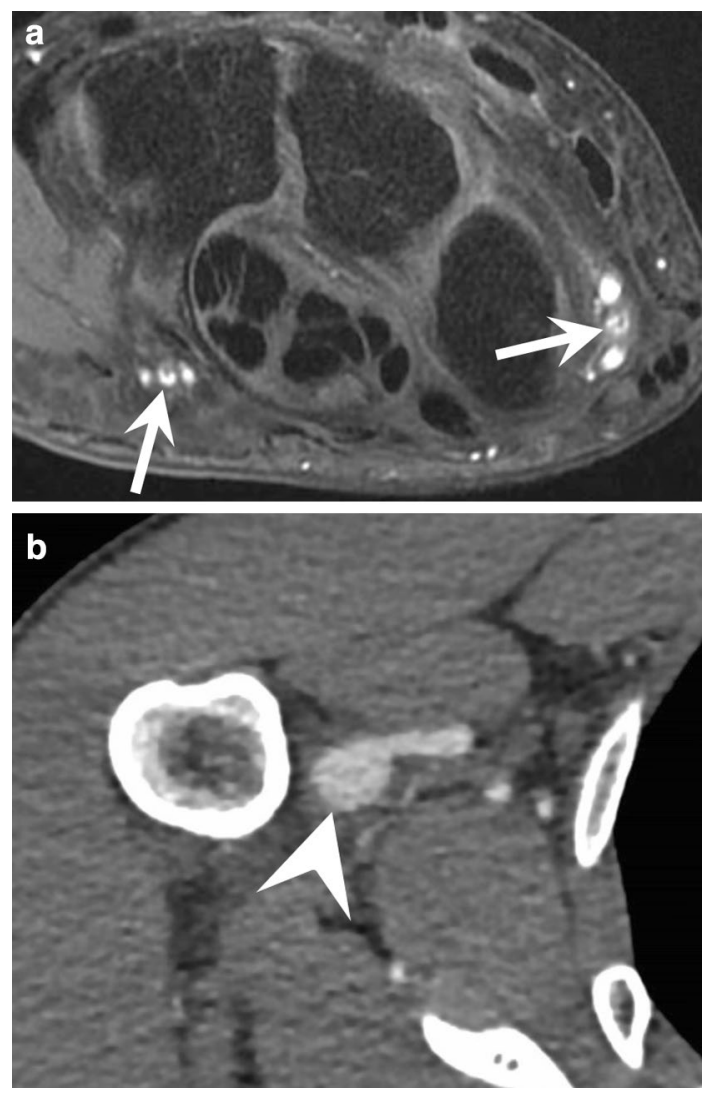

Fig. 8 Distal emboli due to an aneurysm of the axillary artery in a 29-year-old female professional volleyball player. a Axial contrast-enhanced T1-weighted fat-suppressed sequence showing some emboli in the UA and RA (arrows). $\mathbf{b}$ CTA of the entire upper limb showing an aneurysm of the axillary artery haemodialysis access, or axillo-femoral bypass graft [33, 34]. Finally, pseudoaneurysm of the SPA may exceptionally occur after carpal tunnel decompression.

\section{Acute and subacute trauma}

Upper extremity arterial injuries account for up to $50 \%$ of all peripheral vascular injuries. Of these, brachial artery lacerations are the most common, followed by those of the RA and UA, while digital artery lacerations are the least frequent. Digital artery lacerations usually occur secondary to open puncture wounds to the hand, but these injuries may also result from severely displaced fractures, crush injuries, gunshots, and other penetrating wounds. Acute artery lacerations of the hand do not require a CTA, except in cases of associated complex bone lesions or multiple vascular lesions. CTA findings include active extravasation, luminal narrowing, lack of luminal contrast opacification, filling defect, arteriovenous fistula, and pseudoaneurysm (Figs. 5 and 9) [22, 35-37]. Surprisingly, pseudoaneurysms of the hand are exceptional despite the high frequency of hand trauma (Fig. 9). They can affect the RA or UA, the palmar arches, and the digital arteries, presenting clinically as a small mass, sometimes occurring several months after the trauma without any pulsatility. When surgery is required, CTA or MRA provides a global assessment of the vascular network required for treatment planning $[37,38]$.

Occlusion of the digital arteries that results from acute blunt trauma is exceptional [18]. Those described in baseball catchers affect the index finger and are associated with hypertrophy of this finger [39]. Finger artery occlusion has also been described after prolonged strangulation of the fingers due to the wearing of a plastic bag.

\section{HHS}

HHS is in most cases due to repetitive trauma to the UA at the level of the hamulus of the hamatum, leading to a stenosis, an occlusion, and/or an aneurysm of the UA. It is referred to as hammer syndrome because in most cases it originates from repetitive strikes and microtrauma to the ulnar side of the palm of the hand $[14,40]$. However, HHS may also be due to a unique trauma on the palm of the hand.

The clinical manifestations depend on the location and extension of the lesions as well as the configuration of the vascular network. HHS can be asymptomatic, or it can generate Raynaud's phenomenon and acute ischaemic manifestations with embolic digit pulp necrosis. Some clinical symptoms may be misleading because a UA aneurysm can be responsible for a mass effect or cause compression of the ulnar nerve or of its superficial (sensitive) branch (Fig. 10; Additional file 3: Video 3). 

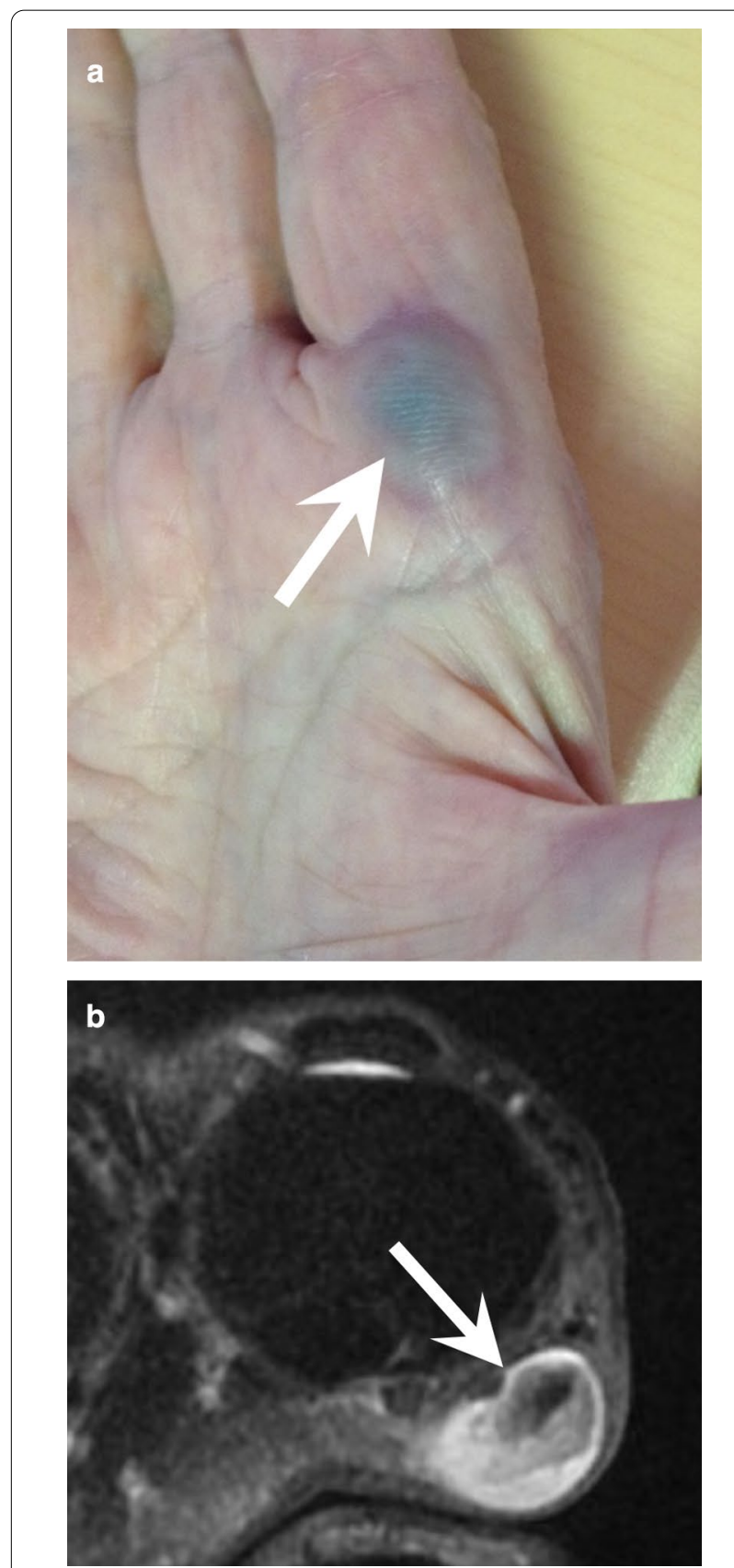

Fig. 9 Occluded pseudoaneurysm of the radiopalmar artery of the index finger in a 79-year-old woman with repetitive microtrauma. a Photograph showing a blue mass under the skin at the level of the metacarpophalangeal joint (arrow). b Axial T2-weighted MR image showing the pseudoaneurysm (arrow) with an intraluminal thrombus

HHS is common in middle-aged, active, smoking men; it generally affects the dominant hand. HHS can be related to sports (racket sports, mountain biking, and breakdancing) or professional activities in which the hand is used to hit, push, or squeeze hard objects. HHS is recognised as an occupational disease in most countries; workers considered 'at risk' include metalworkers, car mechanics, lathe operators, machinists, miners, stonemasons, butchers, bakers, masons and carpenters, lumberjacks, and vibrating tool users.

CTA and/or MRA may be indicated to confirm the diagnosis $[41,42]$. They are mainly performed if surgical treatment is discussed to show the extent of vascular occlusion and its functional impact [43]. It should be noted that the late phase with CTA and contrastenhanced T1-weighted fat-suppressed sequence show a thickening and an enhancement of the arterial wall that underline the thrombus. For these reasons, the diagnosis may be overlooked if only conventional sequences are performed because the thrombus may be misinterpreted as a flow phenomenon (Fig. 11). UA changes initially result in parietal thickening that gradually progresses to occlusion. Occlusion then extends proximally in a variable manner towards the level of the first carpal row or even the distal ulna. Distal compromise of the SPA is also frequent. Intimal lesions may result in clot formation and emboli to the digital arteries (usually of the fourth and fifth fingers). Aneurysms are less common. Arterial dysplasia is frequently associated; it is characterised by a tortuous, helical (corkscrew) deformity of the UA, SPA, and sometimes common digital arteries [14, 18, 40]. This deformity is probably associated with arterial wall fragility and may increase the risk of arterial trauma because of greater exposure of the affected segment of the UA to the hamulus.

Surgical treatment is indicated when there is an aneurysm, ischaemic phenomena, or severe functional impairment resistant to medical treatment. It consists of removing the affected segment and reestablishing flow with venous or arterial bypass. Smoking cessation is obviously recommended, and occupational reclassification may be indicated [43-45].

A so-called thenar hammer syndrome has been described and is exceptional. Repeated microtrauma to the palmar surface of the wrist is likely to generate lesions of the RA that are identical to those described for the UA in HHS. Playing volleyball has been reported to cause this condition.

\section{Hand-arm vibration syndrome (HAVS)}

HAVS is a prevalent occupational disease that affects workers in multiple industries in which vibrating tools are used. The exact prevalence is unknown, but it has been estimated at $50 \%$ among exposed workers. HAVS mainly affects men over 35 years of age. It has three components: vascular, sensorineural, and musculoskeletal. Symptoms vary by intensity and duration of vibration exposure $[45,46]$. Neurosensory signs appear first 

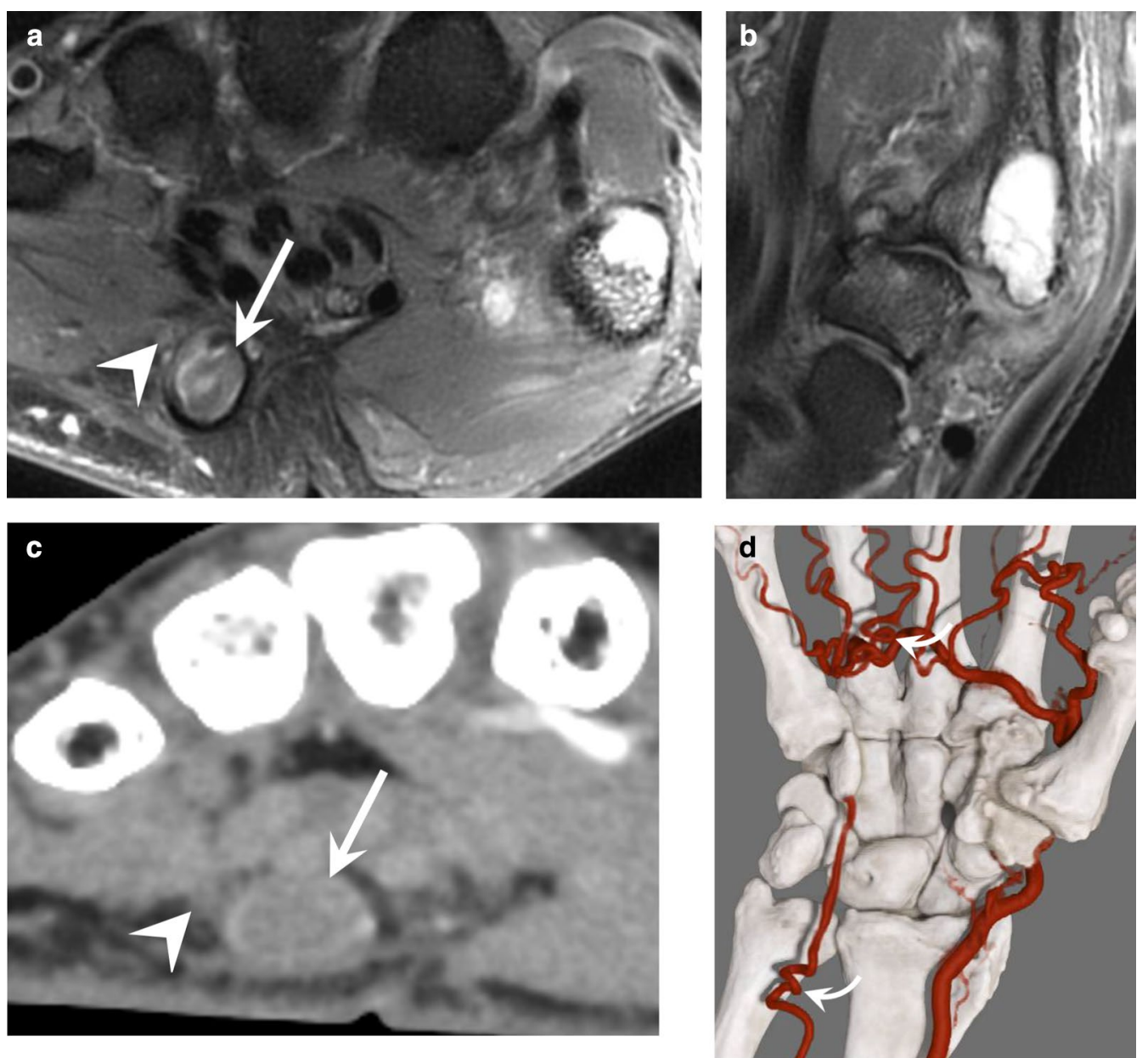

Fig. 10 HHS in a 55-year-old manual worker exposed to different causative factors, including vibrating tools. a, b Axial and coronal T2-weighted MR images showing an occluded aneurysm (arrow) of the distal portion of the distal UA and severe osteoarthritis affecting the trapeziometacarpal joint. c, $\mathbf{d}$ Axial image and Gl with dynamic CTA showing the distal occlusion of the UA, the patency of the SPA fed by the FPMA, a corkscrew deformity of common digital arteries, and the UA at the level of the ulnar head (curved arrow). Note the close relationship between the aneurysm and the superficial branch of the ulnar nerve (arrowhead)

(paresthesia, loss of sensitivity, and carpal tunnel syndrome). Its vascular component, also known as vibration white finger, is a type of Raynaud's phenomenon. Imaging techniques may show the vascular lesions found in HHS because HHS and HAVS share some aetiological factors. Imaging techniques may also show carpal osteoarthritis, carpal bone cysts, tendinopathies, and osteonecrosis of the lunate (Kienböck's disease) (Fig. 12) [45, 47].

HAVS is substantially underrecognised. This underdiagnosis is problematic because early recognition and management of this condition are crucial for preventing progression and improving prognosis. Management involves reduction of vibration exposure, avoidance of cold conditions, smoking cessation, and medication.

\section{Persistent median artery thrombosis}

The persistent median artery may be the site of an occlusion or an aneurysm that causes carpal tunnel syndrome (Fig. 13) [48]. This pathology is rare and its mechanism is unclear.

Intra-arterial drug injections.

Arterial complications result from inadvertent and often repeated arterial puncture during attempted venous access and can lead to acute vascular emergencies. Vascular complications are common in people who inject drugs. They can occur locally at the injection site or at a distant location and may be arterial or venous in nature [49]. They can lead to tissue loss and require amputation in $30 \%$ of patients [50]. Various offending agents have been described, including temazepam, flunitrazepam, 

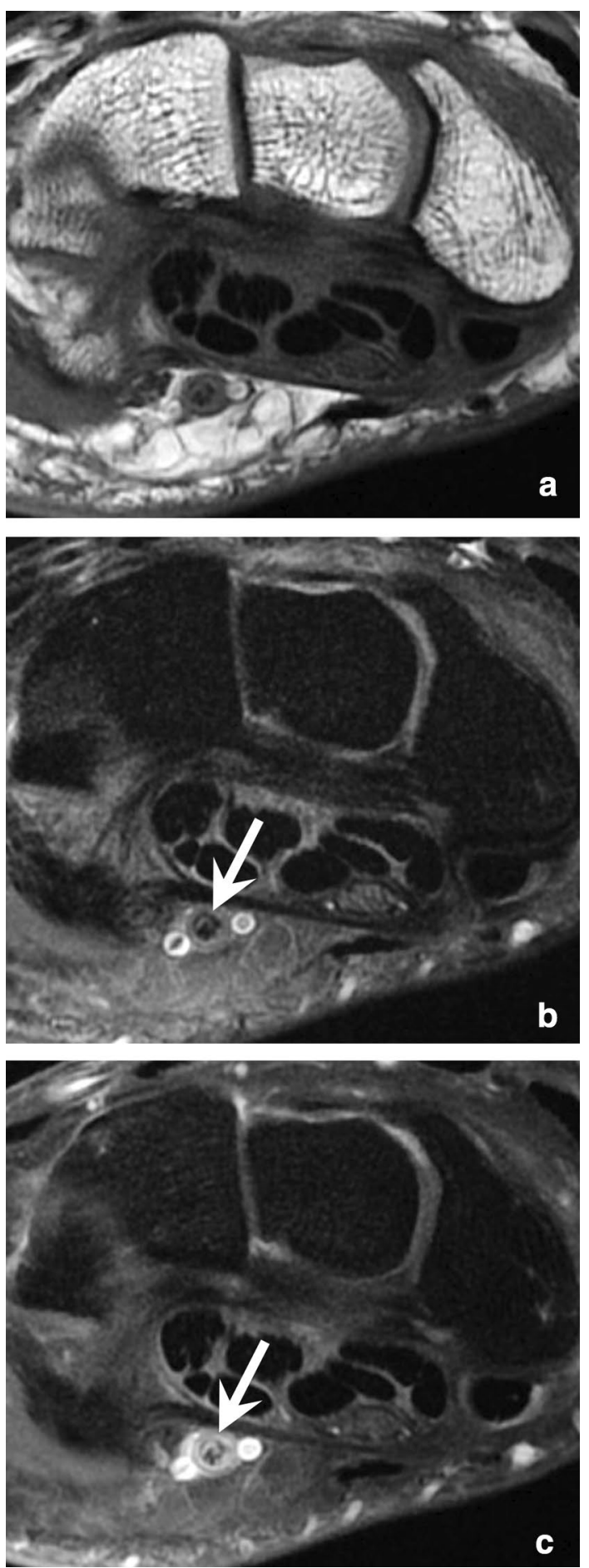

Fig. 11 A pitfall in a case of HHS in a 45-year-old manual worker with an occlusion of the UA. a-c Axial T1-weighted (a) and T2-weighted (b) MR images and contrast-enhanced T1-weighted fat-suppressed sequence (c) showing a subtle thickening and parietal enhancement of the UA (arrow). The thrombus should not be confused with a flow phenomenon
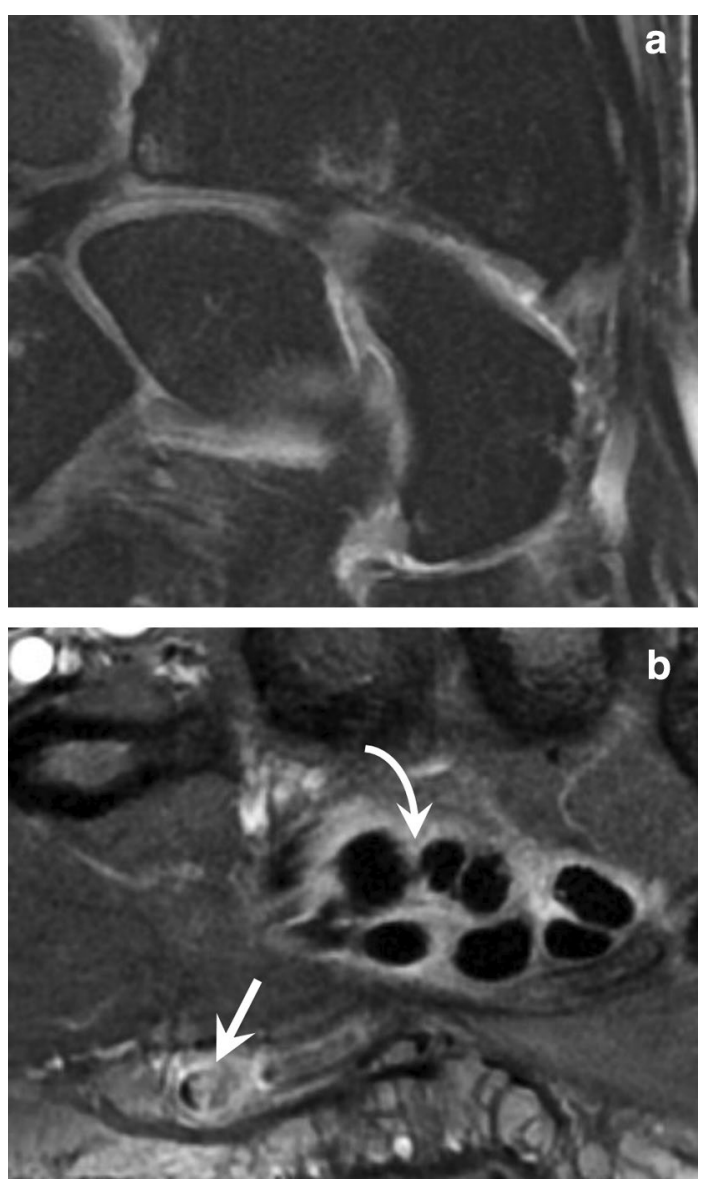

Fig. 12 HAVS in a 62-year-old man. a Coronal T2-weighted MR image showing isolated osteoarthritis of the radioscaphoid compartment of the radiocarpal joint. $\mathbf{b}$ Contrast-enhanced T1-weighted fat-suppressed sequence showing a focal occlusion at the junction of the UA and the SPA (straight arrow) and a tenosynovitis of the flexor digitorum tendons (curved arrow). The UA was otherwise preserved

zolpidem, heroin, midazolam, cocaine, and buprenorphine [51]. Crushed pills lead to a significantly higher incidence of amputation compared with pure drug substances [50]. Associated infections are common and represent a poor prognostic factor.

A multimodal imaging strategy is often required in the assessment of these vascular complications, typically involving a combination of ultrasound and CT (Fig. 14) [49]. Vascular complications may manifest as injury to the vessel wall, pseudoaneurysm or arterial thrombosis with resultant ischaemia or haematogenous spread of a pathogen from the injection site. $\mathrm{CT}$ is the imaging modality of choice for mycotic aneurysms. Gas within the aneurysm is a rare but characteristic sign, which is best seen on CT. Additional imaging features more commonly seen on $\mathrm{CT}$ include a lobulated vascular mass, an 


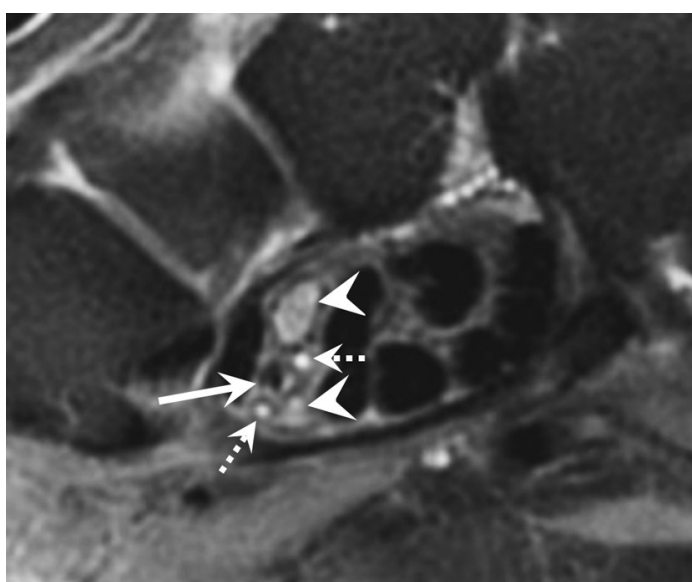

Fig. 13 Persistent median artery occlusion in a 48-year-old woman. Axial T2-weighted MR image showing an occlusion of the persistent median artery (straight arrow) and a bifid median nerve (arrowheads). Note also the small median artery satellite veins (dotted arrows)

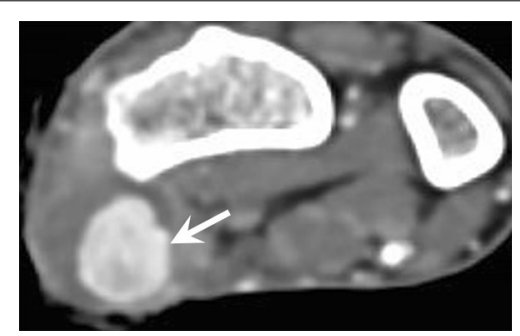

Fig. 14 Pseudoaneurysm of the RA (arrow), after intra-arterial injection of buprenorphine, demonstrated with CTA

irregular and poorly defined arterial wall, peri-aneurysmal soft tissue stranding, and oedema. In addition to the risk of rupture, mycotic aneurysms may also lead to the development of arteriovenous fistulae or serve as a source of sepsis or septic emboli [49]. Thrombolysis and surgical revascularisation may be indicated to restore blood flow to ischaemic tissues in the hand.

\section{Thromboangiitis obliterans}

Thromboangiitis obliterans, also known as Buerger's disease, is a rare, non-atherosclerotic inflammatory disease of unknown aetiology. It typically affects young male smokers (younger than 45 years). Cannabis use has also been implicated. Although Buerger's disease has a worldwide distribution, it is more prevalent in the Middle East and Far East than in North America and Western Europe [52].

This disease primarily affects small- and medium-sized arteries and veins in the upper and lower extremities, usually beginning in the small distal vessels, resulting in distal ischaemia. As the disease progresses, it may involve more proximal arteries. The upper limbs are affected in $25 \%$ of cases [52, 53]. Arthralgia and even arthritis are present in $12 \%$ of cases. Superficial venous thrombosis is also a typical finding.

CTA, MRA, or angiography shows involvement of the small- and medium-sized vessels in the upper (and lower) extremities, including the palmar and plantar arches, the RA and UA, and the digital arteries of the fingers (Fig. 4). The most common imaging findings are segmental occlusive lesions with bridging or corkscrew collaterals around the areas of occlusion. The disease tends to be more severe distally, with interspersed normal vessels. There should be no evidence of atherosclerosis or other proximal source of emboli (e.g. dissections or aneurysms) [53].

The cornerstone of treatment of Buerger's disease is strict abstinence from exposure to all tobacco-containing products. Vasodilator therapy with iloprost should be considered in acute phases, and bypass surgery may be indicated for limb salvage in critical ischaemia.

\section{Systemic diseases and vasculitis}

SSc is a rare multisystemic disease that preferentially affects middle-aged women. Hand involvement is a major feature in patients with SSc, with severe Raynaud's phenomenon in early stages, and skin thickening. Ischaemic digital ulcers may be responsible for major disability. Although rarely indicated for the evaluation of patients affected by SSc, vascular involvement as well as bone and other soft tissue lesions can be identified on CTA or MRA.

Systemic vasculitides affecting the hand are mostly represented by polyarteritis nodosa (PAN). PAN is a systemic necrotising vasculitis that typically affects medium-sized arterial vessels but may also affect smallsized arterial vessels. PAN is usually diagnosed in middle-aged and older adults. Systemic symptoms can be the only complaints but almost every organ can be involved. Characteristic lesions of the hand include multiple short segment stenoses of the proper and common digital arteries, ectasia, and aneurysms with thickening of the vessels [3]. Similar findings have been reported for granulomatosis with polyangiitis and eosinophilic granulomatosis with polyangiitis and microscopic polyangiitis.

\section{(B) Tumours and vascular malformations}

Hand tumours are encountered frequently. Of all soft tissue lesions throughout the body, $15 \%$ are seen in the hand [54]. Lesions with a vascular origin comprise a wide and heterogeneous spectrum of injuries. The International Society for the Study of Vascular Anomalies (ISSVA) classification distinguishes between vascular tumours (lesions with cell proliferation) and vascular 
malformations (due to an innate disruption of vascular morphogenesis) with different pathogenesis, prognosis, and treatment $[55,56]$. Vascular malformations are classified into low-flow malformations (lymphatic, capillary, or most often venous) and high-flow malformations (arteriovenous fistula and arteriovenous malformation $(\mathrm{AVM})$ ). The soft tissue tumours are classified according to the ISSVA and the World Health Organisation (WHO) classification of soft tissue tumours [57].

Some ambiguities still persist because some of these lesions might be classified as tumours or pseudotumours and malformations. In addition, tumours and malformations may also be associated. Furthermore, the current WHO classification of soft tissue tumours recognises three perivascular (pericytic) tumour types: glomus tumours, myopericytoma, and angioleiomyoma [57].

MRI provides valuable information for the assessment and treatment of these lesions. Firstly, MRI can determine the nature of many of these lesions. MRA can also characterise the flow pattern of the vascular malformations to guide treatment towards trans-arterial embolisation for high-flow malformations and percutaneous embolisation for low-flow malformations. Finally, MRI is essential to define the anatomic extent and involvement of various tissue layers, a distinct advantage over ultrasound [7]. Dynamic CTA-due to its higher temporal resolution-is also a valuable technique for the evaluation of high-flow malformations (Fig. 6; Additional file 2: Video 2). It is important to remember that all vascularised lesions do not necessarily have a vascular origin and that histopathologic analysis remains mandatory in most cases $[6,58-60]$.

\section{Vascular malformations}

Vascular malformations of the hand are common. They are frequently responsible for a visible mass or an enlarged finger. Low-flow malformations are much more frequent than high-flow malformations $[1,5,7,9,14,26$, 56, 61-64]. They may affect the skin with a colour change (red or blue). The presence of increased warmth, vascular bruit, or thrill suggests a high-flow component.

An AVM is defined by the presence of a nidus. MRA and CTA demonstrate a very rapid lesion enhancement that occurs in the early phases of arterial enhancement, with dilated afferent arteries and early venous drainage through dilated veins. Flow voids are frequently present on conventional MRI sequences (Fig. 7).

Arteriovenous fistula is characterised by a connection between an artery and a vein and a dilation and rapid enhancement of the vein involved in the hyperdynamic circulation (Fig. 6).

Venous and low-flow malformations are uni- or multifocal lesions with variable size that may affect different anatomical structures of different anatomical compartments. These lesions have a micro- or macrocystic pattern and usually a lobulated appearance, appearing hyperintense on fluid sensitive sequences, without flow voids. Phleboliths or thrombi may be present in intralesional venous lakes. Afferent arteries are of normal size, and there is no early venous drainage. Contrast enhancement is slow and sometimes very delayed or even absent. On dynamic imaging, the earliest lesion enhancement occurs later than $5 \mathrm{~s}$ after arrival of contrast agent in the local arteries $[1,26,61]$.

\section{Vascular tumours}

The ISSVA as well as the WHO classification of soft tissue tumours distinguishes between benign vascular tumours, locally aggressive or low metastatic risk intermediate malignant vascular tumours, and malignant vascular tumours $[55,57,65]$. Some of these tumours preferentially affect the hand (Table 5 ).

Pyogenic granuloma (or lobular capillary haemangioma) is a common benign tumour, usually diagnosed on the basis of its clinical features, although skin biopsies are required to confirm its nature. Pyogenic granuloma is composed of hyperplastic clusters of capillaries arranged in a lobular architectural pattern. Pyogenic granuloma is a misnomer because the condition is not associated with pyogenic infection and it does not histologically represent a granulomatous inflammation. Therefore, the term 'lobular capillary haemangioma' should be preferred. After an initial rapid growth within a few weeks, its size stabilises and rarely exceeds $2 \mathrm{~cm}$. It develops in the superficial dermis-or more rarely in the hypodermisin the mucosal surfaces, and exceptionally in a vein. The superficial lesions take the appearance of a fleshy vascular, friable, and haemorrhagic nodule. These tumours often occur at the site of even minor trauma, a scratch, or an insect bite. They affect both children and adults. They often accompany pregnancy. The tumour is usually solitary, but disseminated forms exist. Imaging techniques show a small, exophytic, and hypervascular tumour associated with a dramatic increase in the vascular flow of the entire finger (Fig. 15; Additional file 4: Video 4) [66].

Intramuscular haemangiomas (IMHs) is a rare entity accounting for less than $1 \%$ of all haemangiomas. There are still some controversies whether they should be classified as vascular malformations or vascular tumours. They affect adolescents and young adults, appear rapidly, and never regress spontaneously. They are mostly composed of mixed vessel types, including lymphatics, large thickwalled veins, a mixture of cavernous-like vascular spaces and capillaries, or a prominent arteriovenous component [57]. IMH usually appears as a lobulated intramuscular hypervascular mass that also contains mature adipose 


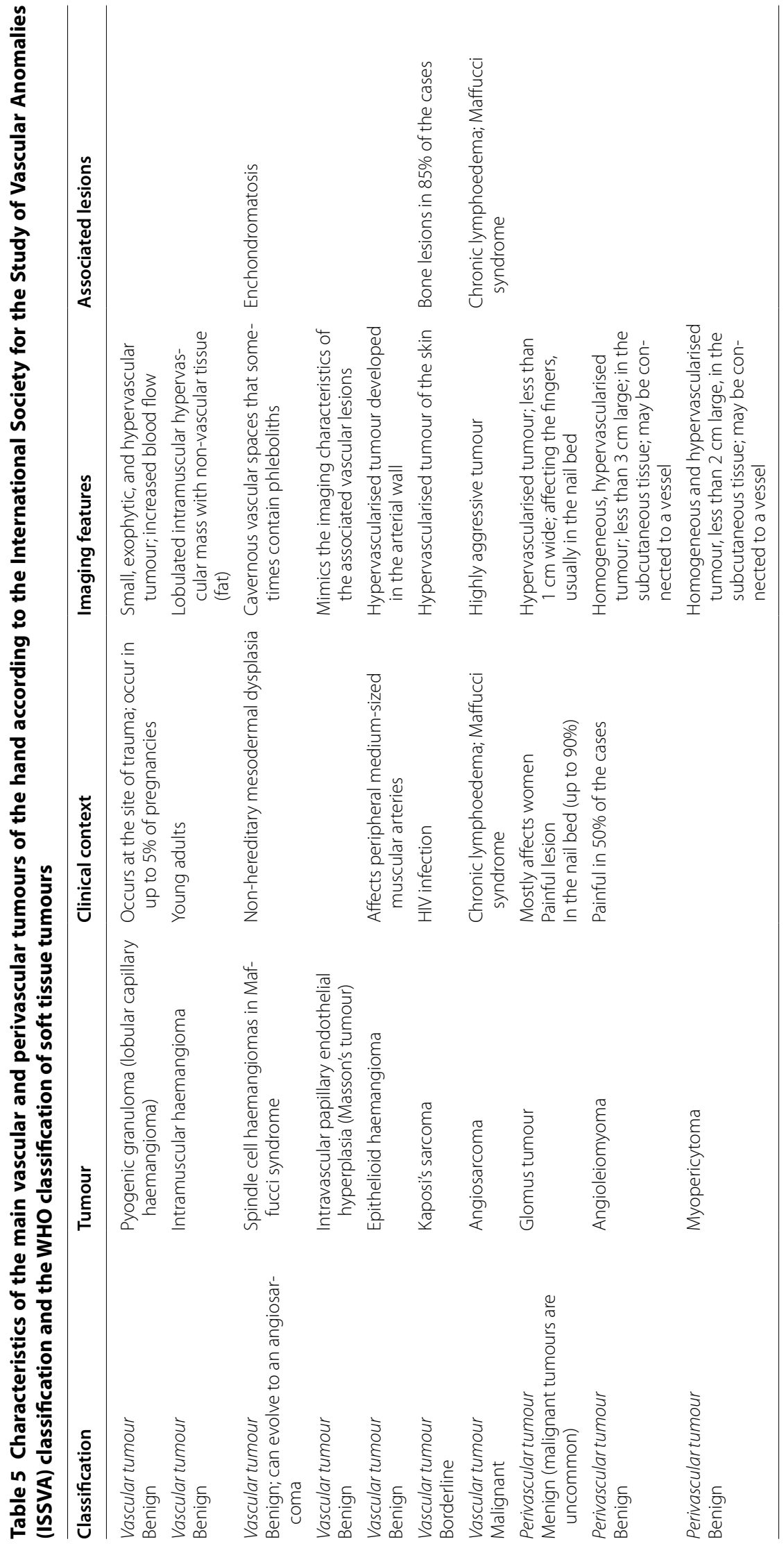



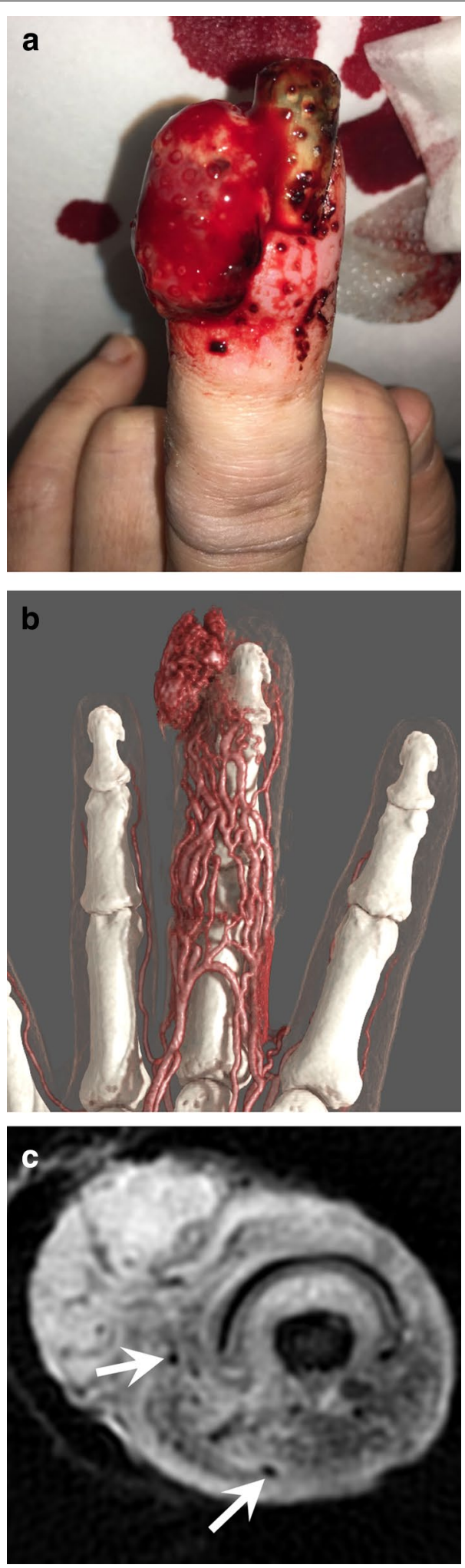

Fig. 15 Pyogenic granuloma of the third finger in a 39-year-old woman who recently gave birth. a Photograph showing fleshy vascular, haemorrhagic exophytic tumour of the distal phalanx, and an enlargement of the finger. $\mathbf{b}$ Dynamic CTA showing an increased vascularity of the entire finger associated with a hypervascular exophytic soft tissue tumour. c Axial T2-weighted MR image showing an exophytic tumour without clear margins associated with oedema and vessels dilations with flow void (arrows) in the soft tissues
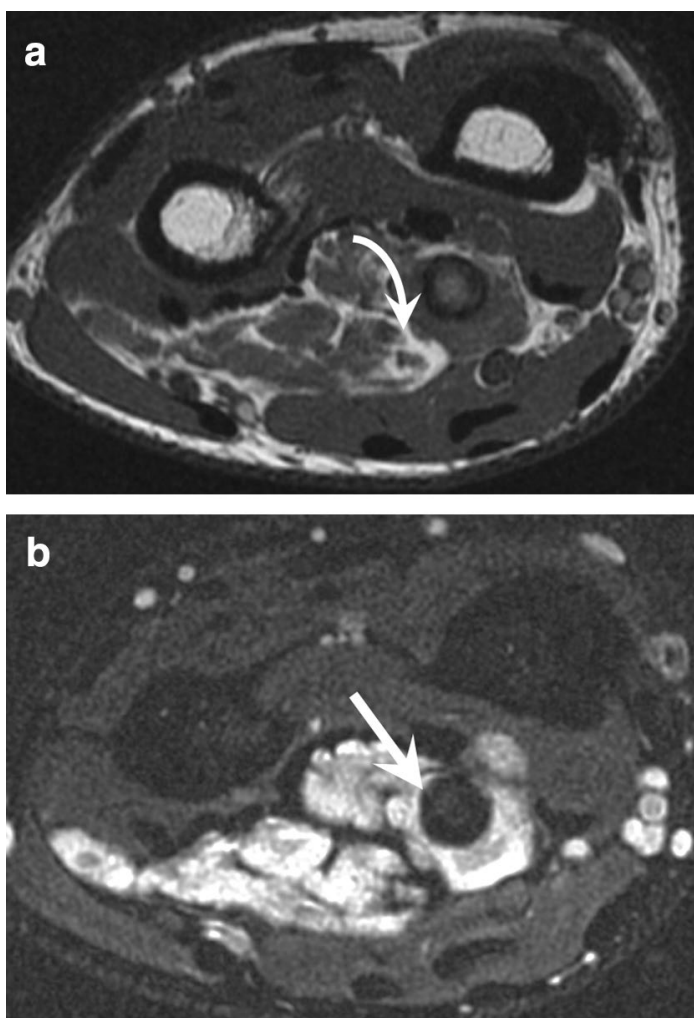

Fig. 16 Intramuscular haemangioma in a 41-year-old man. a, b Axial T1-weighted (a) and T2-weighted (b) MR images showing a large mass infiltrating the flexor digitorum profundus muscle, composed of fatty tissue (curved arrow) and vascular lakes containing thrombi and calcifications (straight arrow)

tissue and sometimes phleboliths, thrombi, or metaplastic ossification (Fig. 16) [67]. These tumours demonstrate an intense enhancement after contrast medium injection, but the vascular flow may be either fast or slow depending upon the vascular composition $[67,68]$.

Spindle cell haemangiomas are benign vascular tumours. They present as slowly growing, vascularappearing, solitary or multiple, dermal or subcutaneous nodules with a predilection for the distal extremities of young adults, especially the hands. Multifocal lesions can be a manifestation of Maffucci syndrome. Maffucci syndrome is a rare, non-hereditary mesodermal dysplasia 

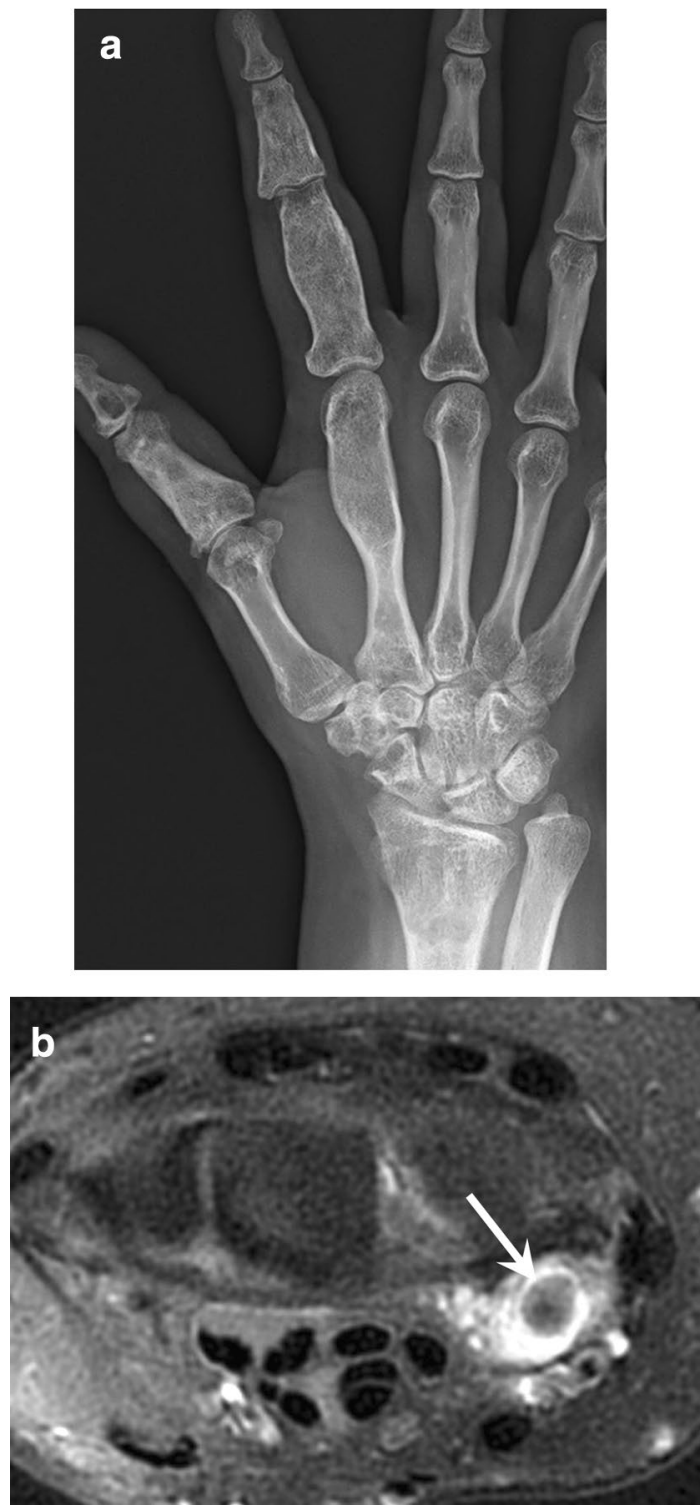

Fig. 17 Maffucci syndrome in a 36-year-old woman. (a) Standard radiography showing the typical multiple enchondroma of the bones of the hand. (b) Axial T2-weighted MR image showing a haemangioma characterised by cavernous vascular spaces containing phleboliths (arrow)

caused by somatic mutations of the IDH1 or IDH2 gene; it is characterised by enchondromatosis associated with spindle cell haemangiomas. The disease begins in childhood with the asynchronous appearance of enchondromas that predominate in the hands and long bones. Haemangiomas appear as small $(<2 \mathrm{~cm})$ lesions that consist of cavernous vascular spaces that sometimes contain phleboliths (Fig. 17). These vascular tumours can evolve into an angiosarcoma in 3\%-5\% of cases [69].

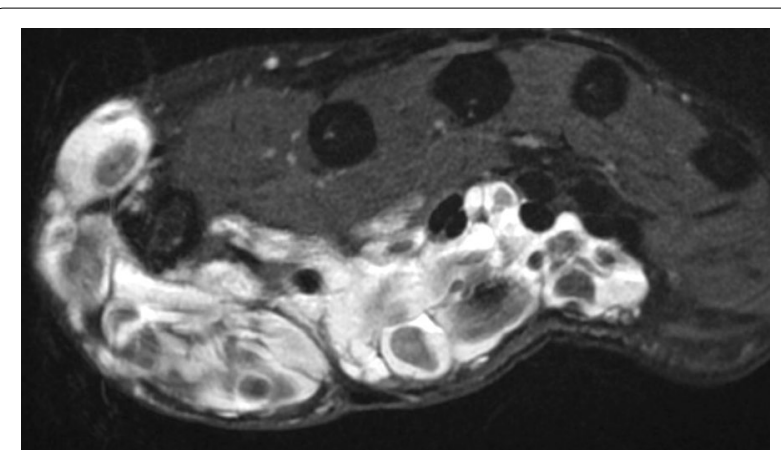

Fig. 18 Secondary intravascular papillary endothelial hyperplasia in a 45-year-old woman taking the aspect of a low-flow vascular malformation affecting the thenar eminence. Axial T2-weighted MR image showing a polylobular mass with multiple cavernous lakes containing phleboliths

Intravascular papillary endothelial hyperplasia (IPEH), also called Masson's tumour, is a benign, reactive, vascular proliferation of endothelial cells that occurs within the vascular lumen associated with an organised thrombus, which may be best described as 'an exuberant form of organising thrombus' [70-72]. IPEH constitutes about $2-4 \%$ of the benign and malignant vascular tumours of the skin and subcutaneous tissues. IPEH can arise from normal blood vessels (primary IPEH) or in vascular malformations (secondary IPEH). The precise pathogenesis of the disease is still unclear, although it seems to be the response to blood vessel injury or thrombosis. There is no age predilection. MRI of primary IPEH shows lesions usually developed in the digits and in a superficial location, with a high peripheral $\mathrm{T} 2$ signal and a variable central T2 signal, a peripheral enhancement (89\%), and an associated dominant vessel (73\%). [65]. Secondary IPEH mimics the imaging characteristics of the associated vascular lesions (Fig. 18). It is important to correlate imaging findings with histology. Although histological evaluation is the main method for diagnosis, IPEH can histologically simulate angiosarcoma, a malignant tumour with a distinct appearance on MRI [70].

Epithelioid haemangioma (also called angiolymphoid hyperplasia with eosinophilia, inflammatory angiomatous nodule, or atypical pyogenic granuloma) is a benign vascular tumour reported at diverse anatomic locations including the skin and arteries. These tumours mostly affect men and show a predilection for the extremities. They may also arise within the walls of peripheral medium-sized muscular arteries, such as the UA or RA. MRI usually shows a tumour with focal intramural growth of the affected vessel (Fig. 19). It is noteworthy that these tumours may also mimic a focal arterial aneurysmal dilatation, a malignant vascular neoplasm, or a 


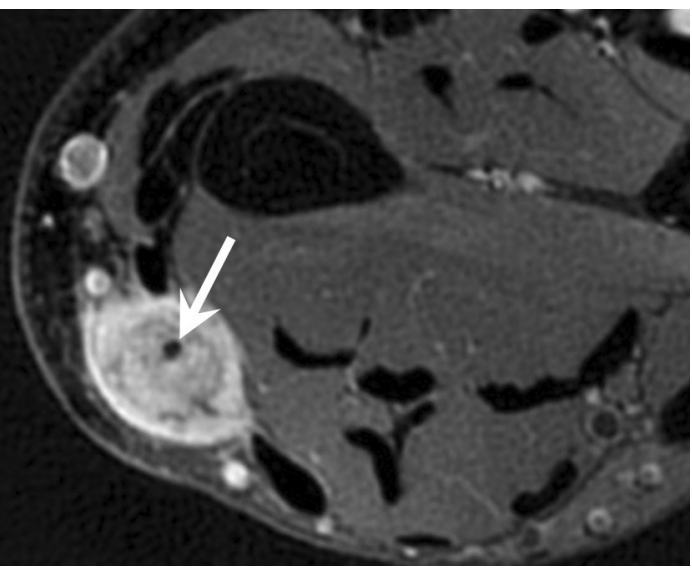

Fig. 19 Epithelioid haemangioma of the RA. Axial T2-weighted MR image showing a hypervascular tumour arising from the arterial wall of the RA associated with narrowing of the vessel lumen (arrow)

classic epithelioid sarcoma. Classic (or distal) epithelioid sarcoma is a malignant mesenchymal neoplasm that affects adolescents and young adults. Classic epithelioid sarcoma commonly occurs in the distal upper extremity and affects mainly volar surfaces of the hand, and CT or MRI demonstrates a multinodular mass that extends along vessels, nerves, and fascial planes [57].

Kaposi's sarcoma frequently-but not exclusivelyaffects the skin, where it is the most common sarcoma. It mainly affects adult men. There are four clinical-epidemiological forms: classic Mediterranean, endemic or African, iatrogenic (frequently in transplanted patients), and epidemic (associated with HIV infection). The causative agent is human herpes virus-8 (HHV-8), which has a particular tropism for endothelial cells and is found in all cases. The appearance of skin lesions varies from a simple purplish plaque (sometimes resembling a haematoma) to an ulcerated tumour. Lymphoedema may be present. Aggressive forms are associated with invasion and destruction of the underlying soft tissue and skeleton. CTA and MRA demonstrate hypervascular round or oval nodules with skin thickening. Lytic bone lesions are present in 85\% of cases (Fig. 20) [73, 74].

Angiosarcoma is an aggressive, malignant endothelial cell tumour of lymphatic or vascular origin. Angiosarcoma of the hand can be divided into primary cutaneous angiosarcoma and secondary angiosarcoma, associated with chronic lymphoedema (Stewart-Treves syndrome) or radiation therapy (Fig. 21). They may also originate from Maffucci syndrome or haemangioma. MRI shows an irregular, highly vascularised mass with foci of haemorrhage, vessels in the tumour, and invasion of the surrounding tissues. It may also appear as small cutaneous
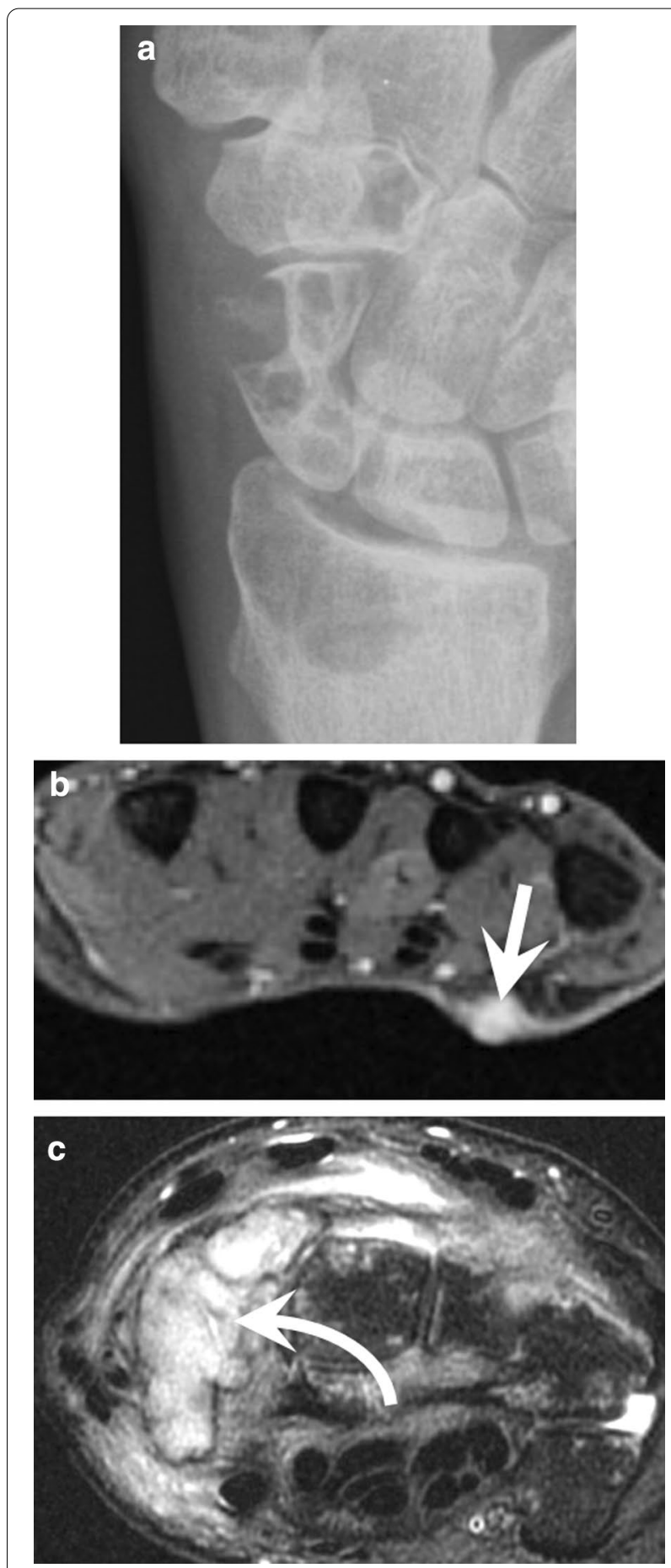

Fig. 20 Epidemic Kaposi's sarcoma in a 40-year-old man. (a) Standard radiography showing bone lytic tumours of the radius, scaphoid, and trapezoid bones. (b, c) Axial T2-weighted MR images showing a small cutaneous tumour of the palm (straight arrow), a tumour invading the scaphoid bone (curved arrow) and soft tissue infiltration 


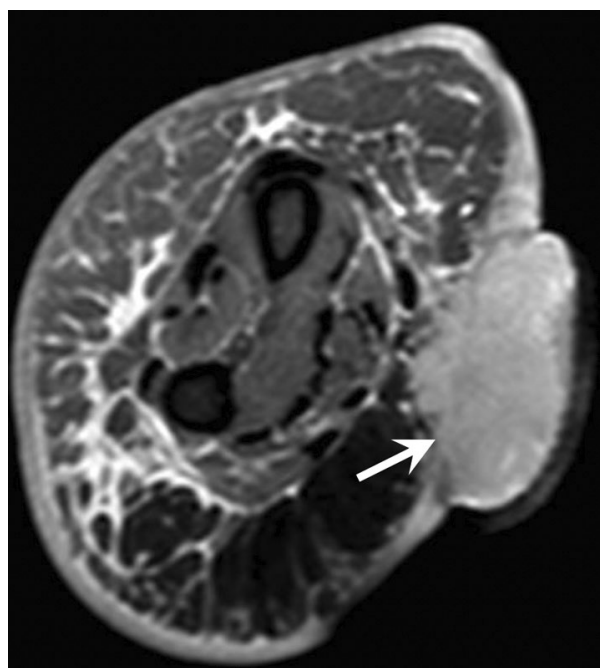

Fig. 21 Stewart-Treves syndrome in a 78-year-old woman with a history of mastectomy with axillary lymph node dissection for breast cancer and chronic lymphoedema. Axial T2-weighted MR image showing a skin exophytic tumour developing at the palm of the wrist corresponding to an angiosarcoma (arrow). Note also the subcutaneous infiltration of soft tissue with a honeycomb pattern and the thickening of dermis indicating a chronic lymphoedema

or subcutaneous nodules or take the appearance of a pseudoaneurysm.

\section{Perivascular tumours}

Glomus tumours are rare benign tumours $(1 \%-5 \%$ of hand tumours) that arise from the glomus bodies. A glomus tumour is a mesenchymal neoplasm composed of cells resembling the perivascular modified smooth muscle cells of the normal glomus body [57]. The proportion of glomus cells, vascular structures, and smooth muscle tissue makes it possible to define three types: solid glomus tumour (75\% of cases), glomangioma, and glomangiomyoma. Glomus tumours also have a nerve component. Malignant glomus tumours are very uncommon [57]. Glomus tumours particularly affect women $[75,76]$.

Glomus tumours are mainly located in the nail bed (75\%-90\% of cases), but they can also develop in its matrix, on the side of the fingers, or in the palms of the hands. The average size is $5-6 \mathrm{~mm}$ and rarely exceeds $1 \mathrm{~cm}$. Most of them are single, but multiple forms exist (2\% of cases).

Distal lesions of the nail bed are visible as a reddishblue spot if the lesion is large enough. The typical clinical triad of localised tenderness, severe pain, and cold sensitivity is highly suggestive of a glomus tumour. More proximal sub-matrix lesions are hidden under the posterior skin fold but may result in longitudinal cracking
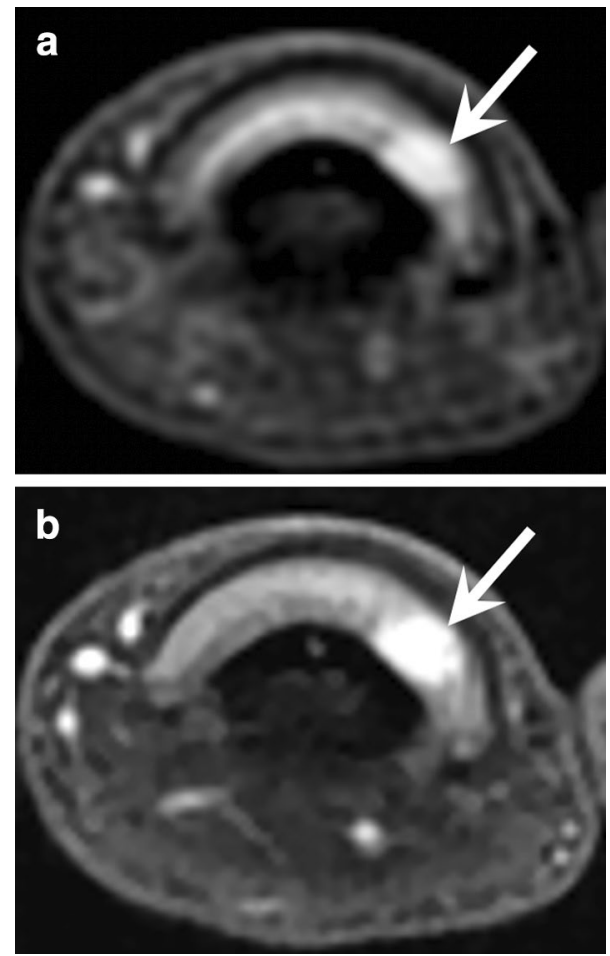

Fig. 22 Glomus tumour of the third finger in a 32-year-old woman. a b Axial T2-weighted MR images and contrast-enhanced T1-weighted fat-suppressed sequence showing a small hypervascularised nodule (arrow) of the ulnar side of the nail matrix

of the nail bed if there is matrix compression [77]. MRI is indicated either as a first-line imaging technique, in particular in the case of painful postoperative recurrence, or after a non-contributory ultrasound examination $[6,63]$. MRI can detect lesions as small as $1.5 \mathrm{~mm}$. This examination usually shows a limited nodule, generally homogeneous, hypointense on T1-weighted images and hyperintense on T2-weighted images, hypervascular with a very intense enhancement on MRA, or contrastenhanced T1-weighted fat-suppressed sequence (Fig. 22) $[78,79]$. An erosion of the dorsal surface of the phalanx may be present with larger tumours. Dynamic CTA with bone subtraction also seems to be an efficient tool for the diagnosis of glomus tumours (Fig. 23; Additional file 5: Video 5) [10, 11]. Complete surgical excision is required to ensure the patient achieves complete relief from the symptoms and to avoid recurrence (4\%-15\% of cases).

Angioleiomyoma is a rare benign vascular smooth muscle tumour arising from the tunica media of vessel walls. Angioleiomyoma affects a wide age range, peaking in the fourth through sixth decades of life. Approximately half of angioleiomyomas are painful. Imaging techniques show a small (less than $3 \mathrm{~cm}$ long), well-circumscribed 


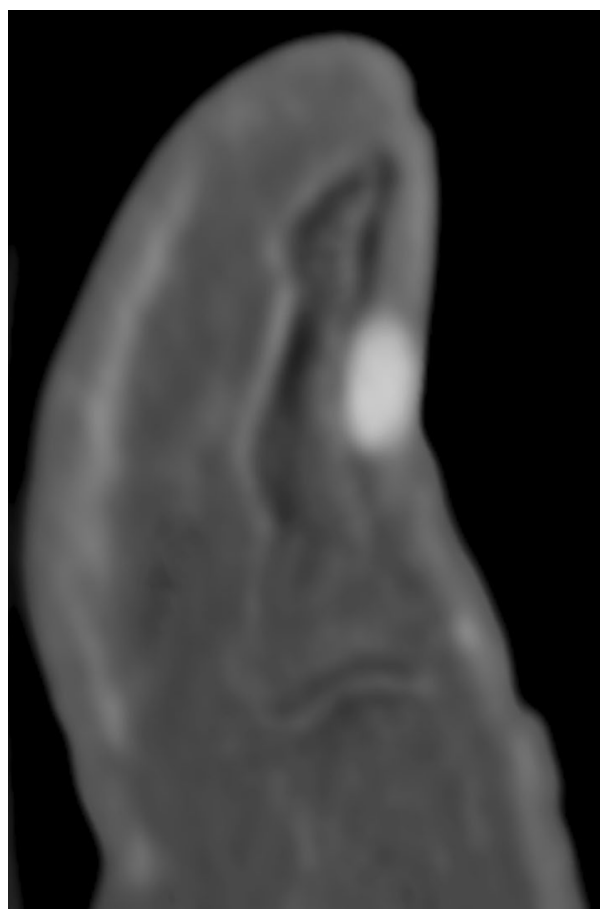

Fig. 23 Glomus tumour of the thumb in a 68-year-old man. Dynamic CTA with bone subtraction showing a small hypervascularised tumour (arrow) of the nail bed

oblong tumour in the subcutaneous fat layer and dermis. The MR pattern is nonspecific with variable enhancement on contrast-enhanced T1-weighted fat-suppressed sequence. However, enhancing vascular structures observed in at least $50 \%$ of the cases, on one or both ends of the mass, are suggestive of the diagnosis [80,81].

Myopericytoma is a rare and distinctive perivascular tumour generally arising in the dermis and subcutis in the distal extremities. Myopericytomas are mostly seen in adults. These tumours are painless. MRI shows a small (less than $2 \mathrm{~cm}$ ), nodular, well-circumscribed subcutaneous tumour with a strong enhancement on contrast-enhanced T1-weighted fat-suppressed sequence. Myopericytomas are usually connected to a vessel and may develop within the lumen of a vessel.

\section{Conclusion}

Vascular lesions of the hand have various origins. US may be the initial imaging modality, but CTA or MRA is also required, providing detailed vascular mapping, functional information, and precise determination of the extent of the lesions. This information is paramount to guide treatment.

\section{Supplementary information}

Supplementary information accompanies this paper at https://doi. org/10.1186/s13244-020-00958-4.

\begin{abstract}
Additional file 1: Video 1. SHR-CTA of the hand (with GI) in a 69-year-old woman that shows the complex arterial network of the hand with a Type A incomplete superficial palmar arch.
\end{abstract}

Additional file 2: Video 2. Dynamic CTA of an arteriovenous fistula fed by the ulnopalmar digital artery of the fourth finger in a 32-year-old patient.

Additional file 3: Video 3. Dynamic CT showing a HHS in a 55-year-old manual worker exposed to different causative factors, including vibrating tools. Note that the delay between each phase is 5 seconds. It takes 35 seconds between the opacification of the RA and the common digital arteries at the level of the metacarpophalangeal joints.

Additional file 4: Video 4. Dynamic CTA showing a pyogenic granuloma of the third finger in a 39-year-old woman characterised by increased vascularity of all the finger associated with a hypervascular exophytic soft tissue tumour

Additional file 5: Video 5. Dynamic CTA with bone subtraction showing a glomus tumour of the nail bed of the thumb in a 68-year-old man

\section{Abbreviations}

AVM: Arteriovenous malformation; CTA: Computed tomography angiography; DPA: Deep palmar arch; FPMA: First palmar metacarpal artery; Gl: Global illumination rendering; HAVS: Hand-arm vibration syndrome; HHS: Hypothenar hammer syndrome; ICM: lodinated contrast medium; IPEH: Intravascular papillary endothelial hyperplasia; ISSVA: International Society for the Study of Vascular Anomalies; MIP: Maximum intensity projection; MPR: Multiplanar reconstruction; MRA: Magnetic resonance angiography; PAN: Polyarteritis nodosa; RA: Radial artery; SHR: Super-high-resolution; SPA: Superficial palmar arch; SSc: Systemic sclerosis; UA: Ulnar artery; US: Doppler ultrasonography; VRT: Volume rendering technique.

\section{Acknowledgements}

We would like to thank Valérie Lamy and Bruno Puyssegur for their work in refining $\mathrm{CT}$ and post-processing protocols.

\section{Authors' contributions}

Each author has made substantial contributions to the conception OR design of the work; OR the acquisition, analysis, OR interpretation of data; OR the creation of new software used in the work; OR have drafted the work or substantively revised it AND to have approved the submitted version (and any substantially modified version that involves the author's contribution to the study); AND to have agreed both to be personally accountable for the author's own contributions and to ensure that questions related to the accuracy or integrity of any part of the work, even ones in which the author was not personally involved, are appropriately investigated, resolved, and the resolution documented in the literature. All authors read and approved the final manuscript.

\section{Funding}

The authors state that this work has not received any funding.

\section{Availability of data and materials}

Materials described in the manuscript, including all relevant raw data, will be freely available to any scientist wishing to use them for non-commercial purposes, without breaching participant confidentiality.

\section{Ethics approval and consent to participate}

We did not receive an IRB approval as in our institution, ethics committee approval is not necessary for retrospective studies using completely anonymised patient data and no changes in the acquisition protocol.

\section{Consent for publication}

Images are entirely unidentifiable, and there are no details on individuals reported within the manuscript. 


\section{Competing interests}

Two of the authors (Alain Blum and Pedro Gondim Teixeira) have a non-remunerated research contract with Canon Medical company. The other authors have non-potential conflicts of interest to disclose.

\section{Author details}

1 Service D'imagerie Guilloz, CHRU Nancy, 54000 Nancy, France. ${ }^{2}$ Department of Hand Surgery, Plastic and Reconstructive Surgery, Centre Chirurgical Emile Gallé, CHRU de Nancy, 54000 Nancy, France. ${ }^{3}$ Vascular Medicine Division and Regional Competence Center for Rare Vascular and Systemic Autoimmune Diseases and Vascular Medicine Division, CHRU Nancy, INSERM UMR-S 1116 University of Lorraine, 54000 Nancy, France.

\section{Received: 25 July 2020 Accepted: 29 December 2020} Published online: 12 February 2021

\section{References}

1. Bannas P, Francois CJ, Reeder SB (2015) Magnetic resonance angiography of the upper extremity. Magn Reson Imaging Clin N Am 23(3):479-493

2. Bozlar U, Ogur T, Khaja MS, All J, Norton PT, Hagspiel KD (2013) CT angiography of the upper extremity arterial system: Part 2-Clinical applications beyond trauma patients. AJR Am J Roentgenol 201(4):753-763

3. Connell DA, Koulouris G, Thorn DA, Potter HG (2002) Contrast-enhanced MR angiography of the hand. Radiographics 22(3):583-599

4. Stepansky F, Hecht EM, Rivera R et al (2008) Dynamic MR angiography of upper extremity vascular disease: pictorial review. Radiographics 28(1):e28

5. Flors L, Leiva-Salinas C, Maged IM et al (2011) MR imaging of soft-tissue vascular malformations: diagnosis, classification, and therapy follow-up. Radiographics 31(5):1321-1340

6. Khaled W, Drape JL (2015) MRI of wrist and hand masses. DiagnInterv Imaging 96(12):1238-1246

7. Fayad LM, Hazirolan T, Bluemke D, Mitchell S (2006) Vascular malformations in the extremities: emphasis on MR imaging features that guide treatment options. Skeletal Radiol 35(3):127-137

8. Bozlar U, Ogur T, Norton PT, Khaja MS, All J, Hagspiel KD (2013) CT angiography of the upper extremity arterial system: Part 1-anatomy, technique, and use in trauma patients. AJR Am J Roentgenol 201(4):745-752

9. Dave RB, Fleischmann D (2016) Computed tomography angiography of the upper extremities. Radiol Clin N Am 54(1):101-114

10. Teixeira PA, Beaumont M, Gabriela $\mathrm{H}$ et al (2015) Advanced techniques in musculoskeletal oncology: perfusion, diffusion, and spectroscopy. Semin Musculoskelet Radiol 19(5):463-474

11. GondimTeixeira PA, Gervaise A, Louis M et al (2015) Musculoskeletal wide detector CT: principles, techniques and applications in clinical practice and research. Eur J Radiol 84(5):892-900

12. Coleman SS, Anson BJ (1961) Arterial patterns in the hand based upon a study of 650 specimens. Surg Gynecol Obstet 113:409-424

13. Rauch A, Teixeira PA, Gillet R et al (2016) Analysis of the position of the branches of the ulnar nerve in Guyon's canal using high-resolution MRI in positions adopted by cyclists. Surg Radiol Anat 38(7):793-799

14. Blum AG, Zabel JP, Kohlmann R et al (2006) Pathologic conditions of the hypothenar eminence: evaluation with multidetector CT and MR imaging. Radiographics 26(4):1021-1044

15. Ruengsakulrach P, Eizenberg N, Fahrer C, Fahrer M, Buxton BF (2001) Surgical implications of variations in hand collateral circulation: anatomy revisited. J Thorac Cardiovasc Surg 122(4):682-686

16. Seiler JG 3rd, Daruwalla JH, Payne SH, Faucher GK (2017) Normal Palmar anatomy and variations that impact median nerve decompression. J Am Acad Orthop Surg 25(9):e194-e203

17. Miletin J, Sukop A, Baca V, Kachlik D (2017) Arterial supply of the thumb: systemic review. Clin Anat 30(7):963-973

18. Blum A, Lecocq, Roch D et al (2009) Angio-scanner et angio-IRM de la main et du poignet. In: SIMS, editor. Poignet et main. Opus XXXVI: Sauramps. p. 283-305.

19. Blum A, Walter F, Ludig T, Zhu X, Roland J (2000) Multislice CT: principles and new CT-scan applications. J Radiol 81(11):1597-1614
20. Oostveen LJ, Boedeker KL, Brink M, Prokop M, de Lange F, Sechopoulos I (2020) Physical evaluation of an ultra-high-resolution CT scanner. Eur Radiol 30(5):2552-2560

21. Gillet R, Teixeira P, Meyer JB et al (2018) Dynamic CT angiography for the diagnosis of patients with thoracic outlet syndrome: correlation with patient symptoms. J Cardiovasc Comput Tomogr 12(2):158-165

22. Fritz J, Efron DT, Fishman EK (2015) Multidetector CT and three-dimensional CT angiography of upper extremity arterial injury. Emerg Radiol 22(3):269-282

23. Blum A, Gillet $R$, Rauch A et al (2020) 3D reconstructions, 4D imaging and postprocessing with $\mathrm{CT}$ in musculoskeletal disorders: past, present and future. Diagn Interv Imaging. 101(11):693-705

24. Dappa E, Higashigaito K, Fornaro J, Leschka S, Wildermuth S, Alkadhi H (2016) Cinematic rendering - an alternative to volume rendering for 3D computed tomography imaging. Insights Imaging 7(6):849-856

25. Johnson PT, Schneider R, Lugo-Fagundo C, Johnson MB, Fishman EK (2017) MDCT angiography with 3D rendering: a novel cinematic rendering algorithm for enhanced anatomic detail. AJR Am J Roentgenol 209(2):309-312

26. Hammer S, Uller W, Manger F, Fellner C, Zeman F, Wohlgemuth WA (2017) Time-resolved magnetic resonance angiography (MRA) at 3.0 Tesla for evaluation of hemodynamic characteristics of vascular malformations: description of distinct subgroups. Eur Radiol 27(1):296-305

27. Murphy DJ, Aghayev A, Steigner ML (2018) Vascular CT and MRI: a practical guide to imaging protocols. Insights Imaging 9(2):215-236

28. Wahl U, Kaden I, Kohler A, Hirsch T (2019) Vascular trauma of the hand-a systematic review. Vasa 48(3):205-215

29. van de Pol D, Kuijer PP, Langenhorst T, Maas M (2012) High prevalence of self-reported symptoms of digital ischemia in elite male volleyball players in the Netherlands: a cross-sectional national survey. Am J Sports Med 40(10):2296-2302

30. Sandoval Y, Burke MN, Lobo AS et al (2017) Contemporary arterial access in the cardiac catheterization laboratory. JACC Cardiovasclnterv 10(22):2233-2241

31. Hahalis G, Aznaouridis K, Tsigkas G et al (2017) Radial artery and ulnar artery occlusions following coronary procedures and the impact of anticoagulation: ARTEMIS (Radial and Ulnar ARTEry Occlusion Meta-AnalysIS) systematic review and meta-analysis. J Am Heart Assoc 6(8):e005430

32. Rashid M, Kwok CS, Pancholy S et al (2016) Radial artery occlusion after transradial interventions: a systematic review and meta-analysis. J Am Heart Assoc 5(1):e002686

33. Chim H, Bakri K, Moran SL (2015) Complications related to radial artery occlusion, radial artery harvest, and arterial lines. Hand Clin 31(1):93-100

34. Sessa C, De Lambert A, Pirvu A, Palacin P, Pichot O (2015) Vascular accessinduced hand ischemia: risks and safe management. Contrib Nephrol 184:164-175

35. Anderson SW, Foster BR, Soto JA (2008) Upper extremity CT angiography in penetrating trauma: use of 64-section multidetector CT. Radiology 249(3):1064-1073

36. Pieroni S, Foster BR, Anderson SW, Kertesz JL, Rhea JT, Soto JA (2009) Use of 64-row multidetector CT angiography in blunt and penetrating trauma of the upper and lower extremities. Radiographics 29(3):863-876

37. Anderson SE, De Monaco D, Buechler U et al (2003) Imaging features of pseudoaneurysms of the hand in children and adults. AJR Am J Roentgenol 180(3):659-664

38. Lucchina S, Nistor A, Stricker H, Fusetti C (2011) False aneurysm of the common digital artery. Is reconstruction with an arterial graft worth the efforts? A case report. Microsurgery. 31(3):246-250

39. Ginn TA, Smith AM, Snyder JR, Koman LA, Smith BP, Rushing J (2005) Vascular changes of the hand in professional baseball players with emphasis on digital ischemia in catchers. J Bone Joint Surg Am 87(7):1464-1469

40. Ferris BL, Taylor LM Jr, Oyama K et al (2000) Hypothenar hammer syndrome: proposed etiology. J Vasc Surg 31(1 Pt 1):104-113

41. Winterer JT, Ghanem N, Roth M et al (2002) Diagnosis of the hypothenar hammer syndrome by high-resolution contrast-enhanced MR angiography. Eur Radiol 12(10):2457-2462

42. Gimenez DC, Gilabert OV, Ruiz JG, Muns CY, Alter JB, Cubells MD (2009) Ultrasound and magnetic resonance angiography features of posttraumatic ulnar artery pseudoaneurysm: a case report and review of the literature. Skeletal Radiol 38(9):929-932 
43. Dethmers RS, Houpt $P$ (2005) Surgical management of hypothenar and thenar hammer syndromes: a retrospective study of 31 instances in 28 patients. J Hand Surg Br 30(4):419-423

44. Kitzinger HB, van Schoonhoven J, Schmitt R, Hacker S, Karle B (2016) Hypothenar hammer syndrome: long-term results after vascular reconstruction. Ann Plast Surg 76(1):40-45

45. Turcot A, Dumitrescu M, Fortier M, Marcotte P, Bernier V, Chabot A. Vibrations mains-bras. Caractérisation du syndrome du marteau hypothénarien chez les travailleurs utilisant des outils manuels. IRSST, editor. Bibliothèque et Archives nationales du Québec 2015.

46. Nilsson T, Wahlstrom J, Burstrom L (2017) Hand-arm vibration and the risk of vascular and neurological diseases - a systematic review and metaanalysis. PLoS One 12(7):e0180795

47. Yesiloz M, Louis M, DeVerbizier J et al (2018) Kienbock's disease: role of cross-sectional imaging in treatment choice and patient follow-up. Eur J Radiol 105:269-282

48. Gassner EM, Schocke M, Peer S, Schwabegger A, Jaschke W, Bodner G (2002) Persistent median artery in the carpal tunnel: color Doppler ultrasonographic findings. J Ultrasound Med 21(4):455-461

49. Delaney FT, Stanley E, Bolster F (2020) The needle and the damage done: musculoskeletal and vascular complications associated with injected drug use. Insights Imaging 11(1):98

50. Devulapalli C, Han KD, Bello RJ, LaPorte DM, Hepper CT, Katz RD (2015) Inadvertent intra-arterial drug injections in the upper extremity: systematic review. J Hand Surg Am 40(11):2262-2268

51. lannuzzi NP, Higgins JP (2015) Acute arterial thrombosis of the hand. J Hand Surg Am 40(10):2099-2106

52. Sasaki S, Sakuma M, Kunihara T, Yasuda K (2000) Distribution of arterial involvement in thromboangiitisobliterans (Buerger's disease): results of a study conducted by the Intractable Vasculitis Syndromes Research Group in Japan. Surg Today 30(7):600-605

53. Dimmick SJ, Goh AC, Cauzza E et al (2012) Imaging appearances of Buerger's disease complications in the upper and lower limbs. Clin Radiol 67(12):1207-1211

54. Hsu CS, Hentz VR, Yao J (2007) Tumours of the hand. Lancet Oncol 8(2):157-166

55. ISSVA classification for vascular anomalies (Approved at the 20th ISSVA Workshop, Melbourne, April 2014, last revision May 2018) [Internet]. International Society for the Study of Vascular Anomalies. 2018. http:// www.issva.org/UserFiles/file/ISSVA-Classification-2018.pdf.

56. Merrow AC, Gupta A, Patel MN, Adams DM (2016) 2014 revised classification of vascular lesions from the international society for the study of vascular anomalies: radiologic-pathologic update. Radiographics 36(5):1494-1516

57. WHO Classification of Tumours. Soft Tissue and Bone Tumours. 5th ed; 2020.

58. Strike SA, Puhaindran ME (2020) Tumors of the hand and the wrist. JBJS Rev 8(6):e0141

59. Sookur PA, Saifuddin A (2011) Indeterminate soft-tissue tumors of the hand and wrist: a review based on a clinical series of 39 cases. Skeletal Radiol 40(8):977-989

60. Mundada P, Becker M, Lenoir V et al (2019) High resolution MRI of nail tumors and tumor-like conditions. Eur J Radiol 112:93-105

61. Ohgiya Y, Hashimoto T, Gokan T et al (2005) Dynamic MRI for distinguishing high-flow from low-flow peripheral vascular malformations. AJR Am J Roentgenol 185(5):1131-1137

62. Kramer U, Ernemann U, Mangold S et al (2012) Diagnostic value of high spatial and temporal resolution time-resolved MR angiography in the workup of peripheral high-flow vascular malformations at 1.5 Tesla. Int $J$ Cardiovasc Imaging 28(4):823-834
63. Drape JL, Feydy A, Guerini H et al (2005) Vascular lesions of the hand. Eur J Radiol 56(3):331-343

64. Taghinia AH, Upton J (2018) Vascular anomalies. J Hand Surg Am 43(12):1113-1121

65. Brahmbhatt AN, Skalski KA, Bhatt AA (2020) Vascular lesions of the head and neck: an update on classification and imaging review. Insights Imaging 11(1):19

66. Lee GK, Suh KJ, Lee JH et al (2010) Lobular capillary hemangioma in the soft tissue of the finger: sonographic findings. Skeletal Radiol 39(11):1097-1102

67. Fuchs A, Henrot P, Walter F et al (2002) Lipomatoustumors of soft tissues in the extremities and the waist in adults. J Radiol 83(9 Pt 1):1035-1057

68. Griffin N, Khan N, Thomas JM, Fisher C, Moskovic EC (2007) The radiological manifestations of intramuscular haemangiomas in adults: magnetic resonance imaging, computed tomography and ultrasound appearances. Skeletal Radiol 36(11):1051-1059

69. Marusic Z, Billings SD (2017) Histopathology of spindle cell vascular tumors. Surg Pathol Clin 10(2):345-366

70. Craig KA, Escobar E, Inwards CY, Kransdorf MJ (2016) Imaging characteristics of intravascular papillary endothelial hyperplasia. Skeletal Radiol 45(11):1467-1472

71. Kim OH, Kim YM, Choo HJ et al (2016) Subcutaneous intravascular papillary endothelial hyperplasia: ultrasound features and pathological correlation. Skeletal Radiol 45(2):227-233

72. Sung J, Kim JY, Yoo C (2016) Intravascular papillary endothelial hyperplasia: magnetic resonance imaging of finger lesions. Skeletal Radiol 45(2):235-242

73. Restrepo CS, Ocazionez D (2011) Kaposi's sarcoma: imaging overview. Semin Ultrasound CT MR 32(5):456-469

74. Javadi S, Menias CO, Karbasian N et al (2018) HIV-related malignancies and mimics: imaging findings and management. Radiographics 38(7):2051-2068

75. Lee W, Kwon SB, Cho SH, Eo SR, Kwon C (2015) Glomus tumor of the hand. Arch PlastSurg 42(3):295-301

76. Morey VM, Garg B, Kotwal PP. Glomus tumours of the hand: review of literature. J Clin Orthop Trauma 2016;7(4):286-91.

77. Netscher DT, Aburto J, Koepplinger M (2012) Subungual glomus tumor. J Hand Surg Am 37(4):821-823

78. Drape JL, Idy-Peretti I, Goettmann S et al (1995) Subungual glomus tumors: evaluation with MR imaging. Radiology 195(2):507-515

79. Trehan SK, Athanasian EA, DiCarlo EF, Mintz DN, Daluiski A (2015) Characteristics of glomus tumors in the hand not diagnosed on magnetic resonance imaging. J Hand Surg Am 40(3):542-545

80. Kang BS, Shim HS, Kim JH et al (2019) Angioleiomyoma of the extremities: findings on ultrasonography and magnetic resonance imaging. J Ultrasound Med 38(5):1201-1208

81. Yoo HJ, Choi JA, Chung JH et al (2009) Angioleiomyoma in soft tissue of extremities: MRI findings. AJR Am J Roentgenol 192(6):W291-W294

\section{Publisher's Note}

Springer Nature remains neutral with regard to jurisdictional claims in published maps and institutional affiliations.

\section{Submit your manuscript to a SpringerOpen ${ }^{\odot}$ journal and benefit from:}

- Convenient online submission

- Rigorous peer review

- Open access: articles freely available online

- High visibility within the field

- Retaining the copyright to your article

Submit your next manuscript at springeropen.com 